دراسة تحليلية لارجة رضا خريجي برنامج العلوم الاقتصادية والاجتماعية كلية الزراعة جامعة عين شمس فمس

$$
\begin{aligned}
& \text { في ضوء متطلبات سوق العمل } \\
& \text { محمد عثمان عبدالفتاح'، هبة نور الدين محمد' }
\end{aligned}
$$

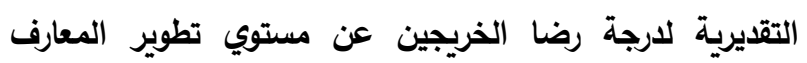

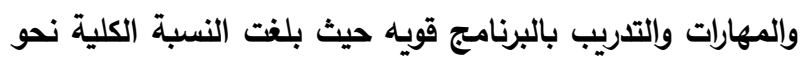

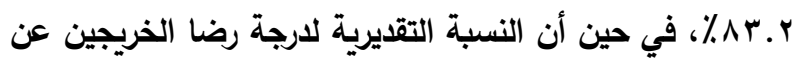
أداء سوق العمل اتجاههم متوسطة حيث بلغت النسبة الكلية نحو

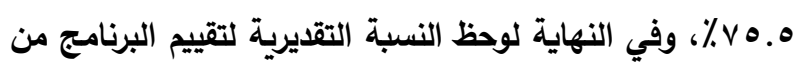

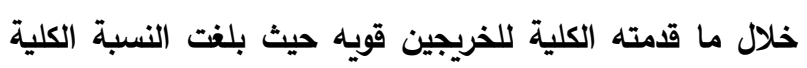

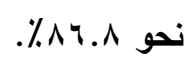

الكلمات الدالة: رضا الخريجين، سوق العمل، جامعة عين

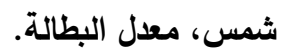

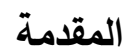

الجامعات تمثل محور الاتصال المعرفي والتقدم الثقافي والرقي الاجتماعي، ويقع على عاتقها مسئولية تهيئة الكفاءات

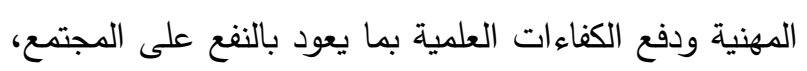

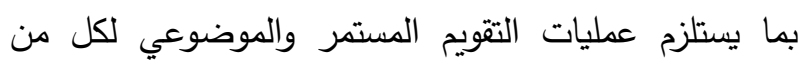
يعمل بالجامعة ومن الخبرات التي يكتسبها الطلاب خلال

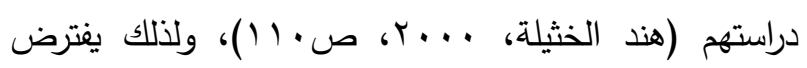

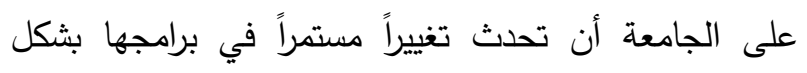
يتناسب والتغيرات المحيطة بها وحاجة سوق العمل والإهتمام

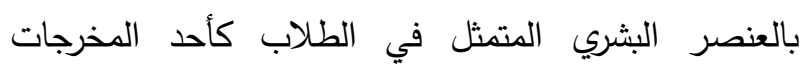

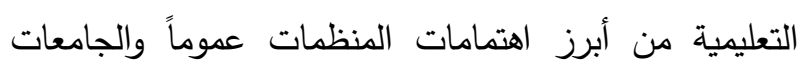

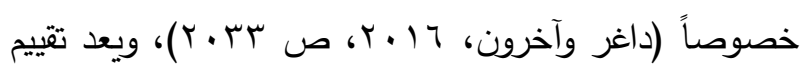
المخرجات الطلابية من المصادر الرئيسية التي تعتمد عليها الجامعات في الإعداد والتخطيط والتطوير للبرامج والخدمات التئية والمرافق الجامعية (Terenzini, 1995, p28)، ويعتبر

$$
\text { الملخص العربى }
$$

يستهاف هذا البحث تحديد معدل البطالة لخريجي برنامج

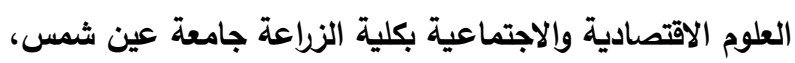

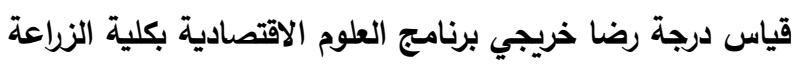

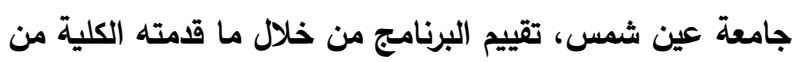

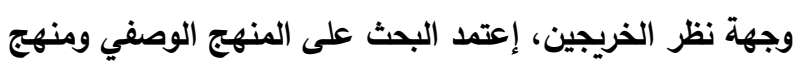

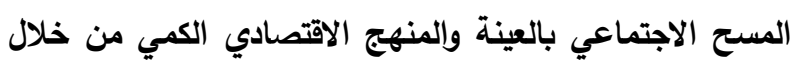

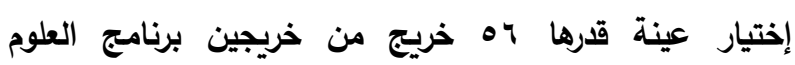

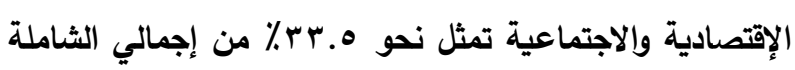

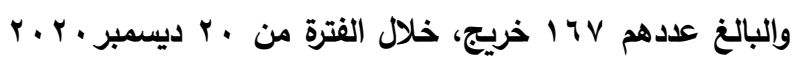

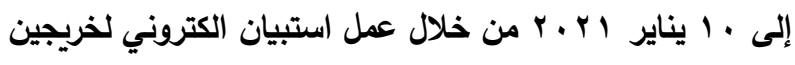

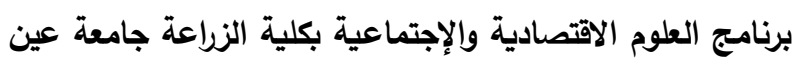

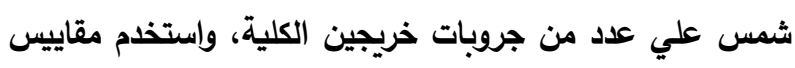

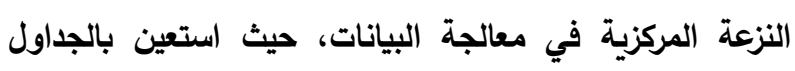

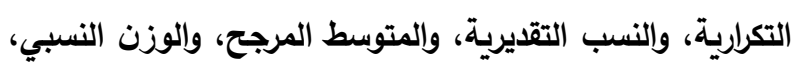
والمتوسط الهنسي بالإضافة إلى حساب معدل البطالة.

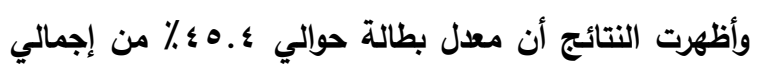

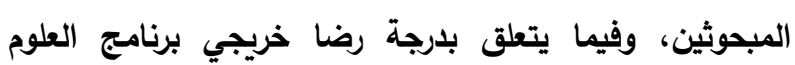

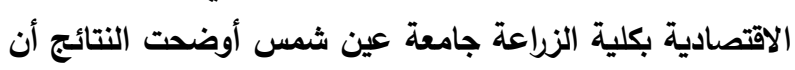

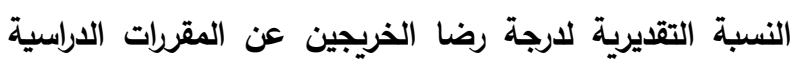

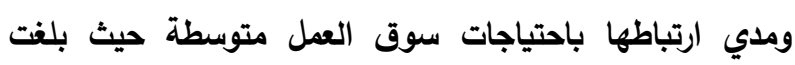

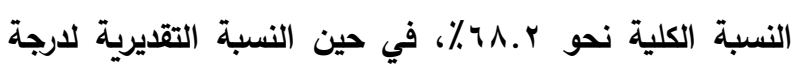

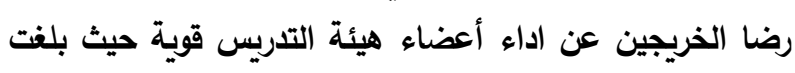

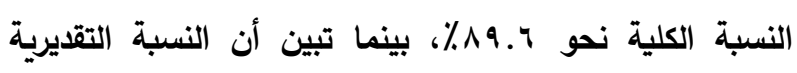
لارجة رضا الخريجين عن مستوي أداء الذدمات بالكلية متوسطة

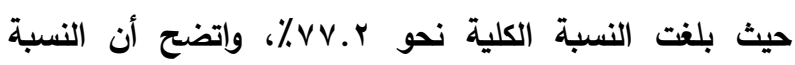

\footnotetext{
'قسم الاقتصاد الزراعي - كلية الزراعة - جامعة عين شمس

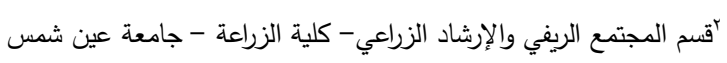

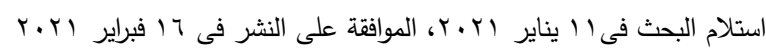




$$
\text { مجلة الإسكندرية للتبادل العلمى - (مجلد بـ العدد () يناير - مارس (Y.r }
$$

وخبرات عامة ادت إلي صقل قدراتهم التنافسية لمواجهة سوق

$$
\text { العمل، لذلك يستهدف البحث الحالي: }
$$

1-تحديد معدل البطالة لخريجي برنامج العلوم الاقتصادية والاجتماعية بكلية الزراعة جامعة عين شمس.

ץ-قياس درجة رضا خريجي برنامج العلوم الاقتصادية بكلية

$$
\text { الزراعة جامعة عين شمس. }
$$

r-تقييم البرنامج من خلال ما قدمته الكلية من وجهة نظر

$$
\text { الخريجين. }
$$

\section{الإطار النظري والإستعراض المرجعي}

يشير مفهوم الرضا إلى الثعور بالسعادة والابتهاج الذي

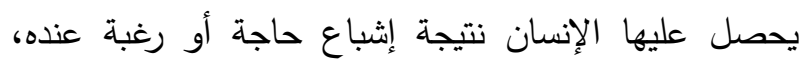
وعرف (Hom, 2002) الرضا بأنه الحالة التي يشعر بها الفرد عن النتائج التي استجابت لتوقعاته، وأن الرضا أو عدم الرضا لا يكون نتاج تقديم الخدمة فقط ولكنه يتأثر بتوقعات الفرد المسبقة عن نوعية الخدمة المقدمة أو جودتها، ويعرف الرضا أيضاً بأنه الحالة الثعورية التي تصاحب بلوغ الفرد غايته وإشباع حاجاته ورغباته التي يتطلبها عن طريق التفاعل بين العوامل الثخصية للفرد نفسه والعوامل الخاصة بطبيعة

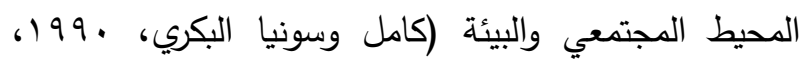

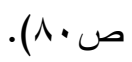

يمكن قياس الرضا عن الخدمات الجامعية من خلال قياس الفجوة بين فهم المستفيدين من الخدمة وتوقعاتهم لها، أو من خلال تقييم مدى توافر العناصر التي تمثل جودتها، ويعتبر من أكثر النماذج استخداما في المؤسسات التعليمية، ويقوم على تحديد إدراك جودة الخدمة من خلال قياس الفرق بين تقديرات المستقيدين المتوقعة من جودة الخدمة ونوعيتها، فإن كانت تقديرات الجودة أقل من التوقعات في نوعية الخدمة تبين أن هنك تدنيا في الخدمة المقدمة ووجود فجوة. (القضاة

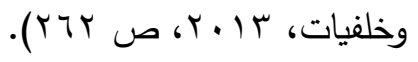

قياس رضا الطلاب واستطلاع أرأؤهم أحد مدخلات عمليات التقييم الجامعي، وتقديم نظرة عامة عن الصورة التي تكونت لاى الطالب عن جامعته خلال الفترة التي قضاها على مقاعد (Kuh, 1992, p116) الدراسة التي تستخدم لقياس جودة الخدمة في المؤسسات التعليمية هو تحقيق أعلى مستويات رضا من قبل الطلبة عن كل ما تقدمه الجامعة من خدمات، وكذلك رضا أفراد المجتمع عن الخدمات التي تقدمها الجامعة للمجتمع، ورضاهم عن مستوى الخريجين الذين يلتحقون بسوق العمل (الحدابي وعكاشة، T . . Y، ص V)، ويُعد الخريجون من أهم مخرجات التعليم العالي التي تسعى المؤسسات التعليمية إلى الارتقاء بجودتها، ويركز هذا النوع من المخرجات على المعرفة الأساسية والمعلومات التي تثكل البنية التحتية لجودة الخريجين، يرتبط المستوى النوعي للخريجين بقدرات الطلبة على متابعه وفهم الأسس والمبادئ المهنية، وكذلك فهم وسائل تطبيقها في ميادين

$$
\text { العمل (الطائي وآخرون،م. . . r). }
$$

\section{المشكلة البحثية والأهداف}

رضا الطلاب أصبح قضية في غاية الأهمية بالنسبة للجامعات وإدارتها من أجل تحسين أداء المؤسسات التعليمية، لذلك يتعين على الجامعات دراسة آراء الطلاب حول جميع جوانب الحياة الأكاديمية لمعرفة درجة الرضا، والتركيز على ضمان جودة الخدمات التعليمية المقدمة، وعلى تلبية توقعات واحتياجات عملائها الأساسيين في العملية التعليمية والممثلين لعينة المخرج النهائي وهم الطلاب. (نعيمة البوقري وسمر

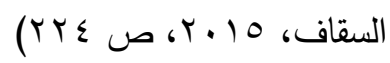
وتتمثل مشكلة أي مؤسسة تعليمية عامة وكلية الزراعة جامعة عين شمس منها بصفة خاصة في كيفية الاستدلال علي نجاح رسالتها وبلوغ اهدافها علي أرض الواقع، ولما كان الخريج يعتبر أحد أهم المخرجات التي تنافس بها المؤسسة التعليمية في سوق العمل، كان لزاماً قياس مدي رضا هؤلاء الخريجين عما اكتسبوه من مهارات معرفية وذهنية ومهنية 
خلال فترة أقل من سنة بعد تخرجهم. كما تبين أن إيجاد الوظائف من خلال العائلة أو الأصدقاء هي الطريقة الثنائعة

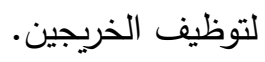

واستهدفت دراسة (أسماء عبدالله، 19 • ب) التعرف على

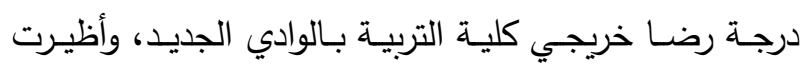

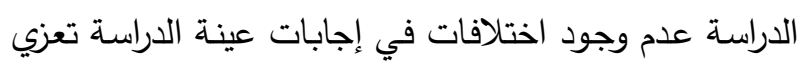

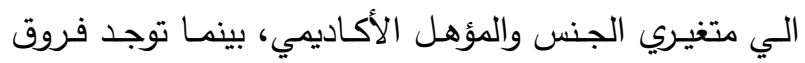
تعزي الي متغير التخصص العلمي، وقد توصلت الدراسة الي لئي

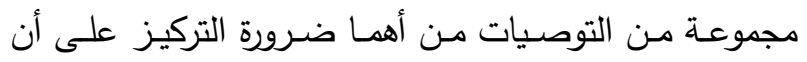
يكون رضا الطلبة واحد من معايير التقييم الأكاديمي والإداري الذاتي والخارجي.

\section{الطريقة البحثية}

اعتمدت الدراسة على عدة مناهج بحثية حيث استخدم

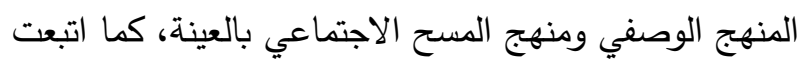
الدراسة الدنهج الاقتصادي الكمي لاستخلاص النات النتائج

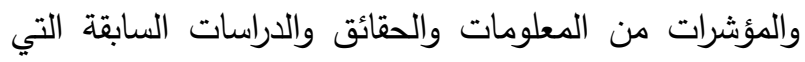
أمكن الحصول عليها لتكميم الظاهرة موضع الدراسة.

\section{المجال الجغرافي والبشري للدراسة}

تم اختيار كلية الزراعة جامعة عين شمس لتمثل الإطار الجغرافي للبحث، أعقب ذلك اختيار خريجي برنامج العلواري

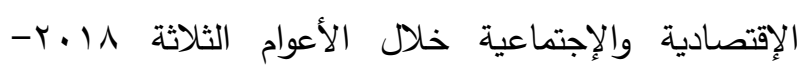

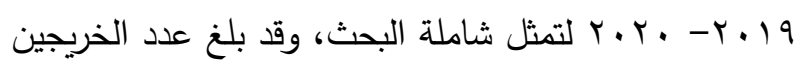

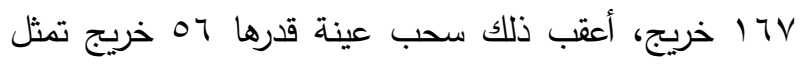
نحو 0.rr\% من إجمالي الثناملة.

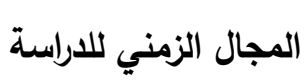

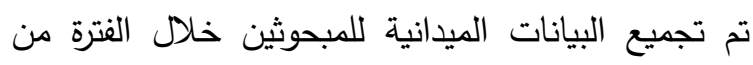

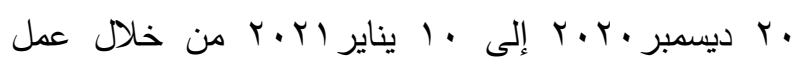

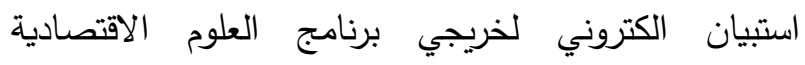
والإجتماعية بكلية الزراعة جامعة عين شمس علي عدد من الكني جروبات خريجي الكلية.
وتتاولت الدراسات الدختلفة رضا الطلاب، حيث أشارت الدراسة التي قام بها (Aldosary, 1999) عن الرضا

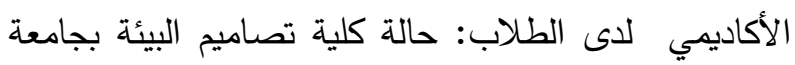

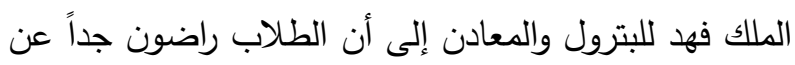

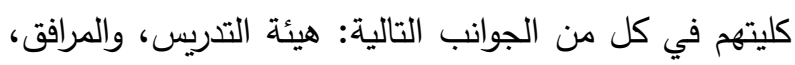
والمناهج الدراسية.

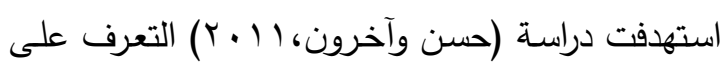
درجة رضا الطلبة الخريجين عن الدراسة في كلية التربية جامعة السلطان قابوس، واستخدمت الدراسة استبياناً لقياس درجة الرضا يتكون من (V9) فقرة توزعت على خمسة أبعاد أبعاد،

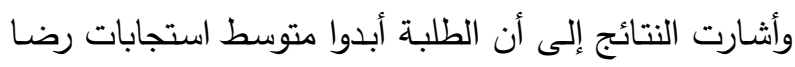

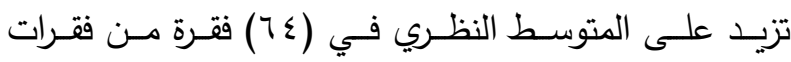

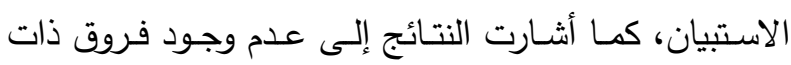

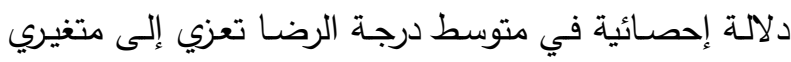
الجنس أو المؤهل الأكاديمي أو التفاعل بينهما. واستهدفت دراسة (نعيمة البوقري وسمرالسقاف، 10 • ب) دراسة أثر جودة الخدمة على رضـا الطالبات في مؤسسات

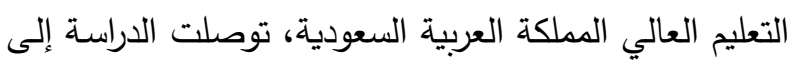

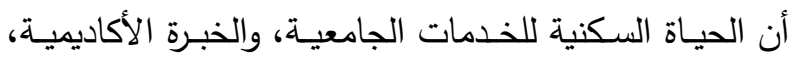

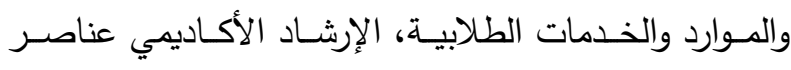
مهمة جدا، بينما عنصر فرص تتمية الشخصية فهو مهم.

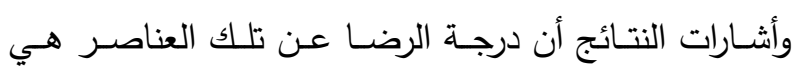
متوسطة.

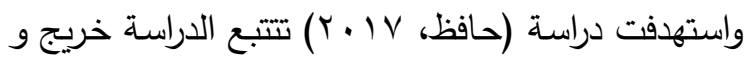

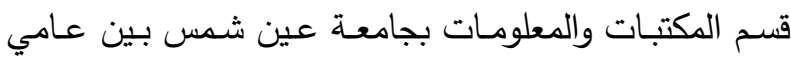

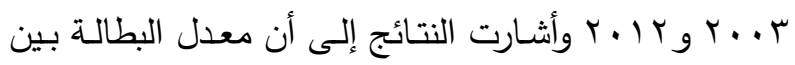

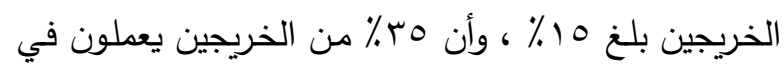

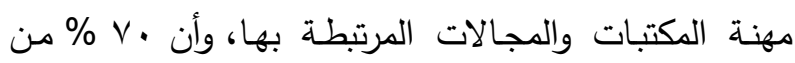
الخريجين يلتحقوا بوظائف 
r- تقييم الخريجين للبرنامج: ويقصد به تقييم الخريجين

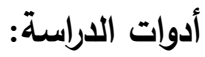
للبرنامج من حيث الخبرات التعليمية، جودة الارشاد الاكاديمي، اداء أعضاء هيئة التدري، الأنشطة والحياة الطلابية، جودة البرنامج، وتتم الإجابة بالإختيار بين ثلاثة بدائل وهي ممتاز، متوسط، مقبول، وقد أعطيت لهذه

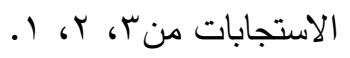
؟- معدل البطالة: وهي نسبة غير المشتغلين (المتعطلين) من القوة العاملة إلى إجمالي قوة العمل، ويستخدم كمؤشر اقتصادي للحكم على سوق عمل الخريجين بالبرنامج. أدوات التحليل الإحصائي استخدم البحث بعض مقاييس النزعة المركزية في معالجة

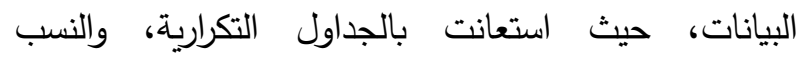

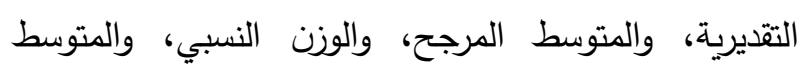
الهندسي بالإضافة إلى حساب معدل البطالة. توصيف عينة البحث: يتضح من جدول (1): توصيف عينة البحث لخريجي برنامج العلوم الاقتصادية والاجتماعية بكلية الزراعة جامعة لونة لوصلية عين شمس بالنسبة لمتغير السن يتبين أن عدد الخريجين البالغ عمرهم r سنه وهو أقل سن بلغ عددهم r خريجين

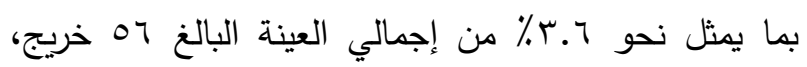
كذلك بلغ عدد الخريجين البالغ عمرهم سب سنه 19 خريج بما يمثل نحو 9.بr\% من إجمالي العينة، بينما بلغ عدد

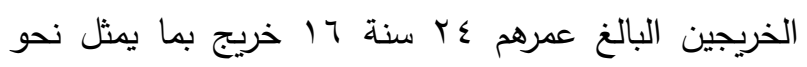

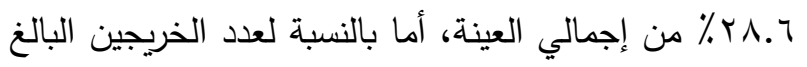

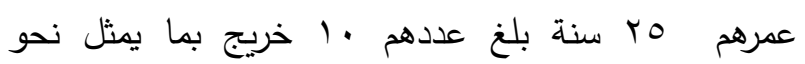

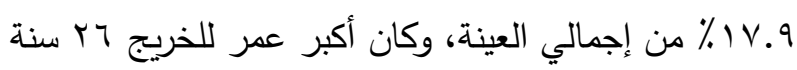

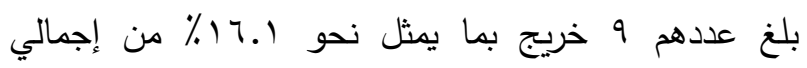

اعتمد البحث بشكل أساسي فى الحصول علي البيانات وتسجيلها علي تصميم إستبانة كأداة للدراسة تكونت دن لئن ثماني وخمسون فقرة مقسمة علي خمسة محاور هي: درجة رضا الخريجين عن المقررات الدراسية ومدي ارتباطها باحتياجات سوق العمل، درجة رضا الخريجين عن اداء اعضاء هيئة التدريس، درجة رضا الخريجين عن مستوي أداء الخدمات بالكلية، درجة رضا الخريجين عن مستوي المعارف والمهارات والتدريب بالبرنامج، رضا الخريجين عن أداء سوق باته العمل اتجاههم، وقد تم التحقق من صدق أداة الدراسة بعرضها على مجموعة من الخبراء والمحكمين المختصين الذين أبدوا بعض الملاحظات والإقتراحات، وقد تم الإستفادة من جميع الملاحظات والمقترحات والتغذية الراجعة التي تم الحصول عليها وذلك بهدف تحسين وتطوير النموذج. المفاهيم الاجرائية وطرق القياس 1- درجة رضا الخريجين عن البرنامج: يعتبر رضا الطلاب مقياساً لفعالية مؤسسات التعليم العالي، وضنصراً أولوياً واستراتيجياً لمهمتها وخططها المستقبلية، ويقصد به في هذه الدراسة مدى رضا الخريجين عن برنامج العلوم الاقتصادية والاجتماعية، وذلك من خلال إستبانة أعدها الباحثين كأداة للدراسة، وتكونت الاستبانة من ثماني وني وخمسون فقرة مقسمة على خمسة محاور، بحيث تتم الإجابة بالإختيار بين ثلاث بدائل وهي راضي، محايد،

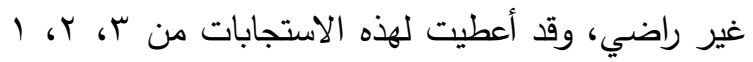
حسب إتجاه العبارة، حتى يتسنى جمعها معا لإيجاد درجة كلية معبرة عن درجة رضا الخريجين عن برنامج العلوم الإقتصادية والإجتماعية. ץ- احتياجات سوق العمل: مجموعة المعارف والمفاهيم والمهارات الأدائية التي ينبغي على الخريج الاتصاف بها في ضوء متطلبات المجتمع 
ويلاحظ من متغير النوع أن عدد خريجي البرنامج من

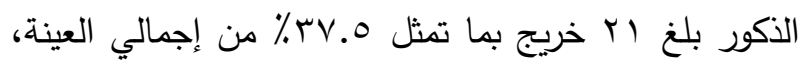

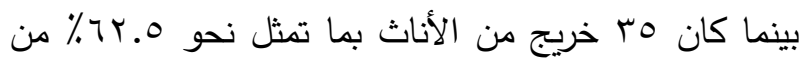

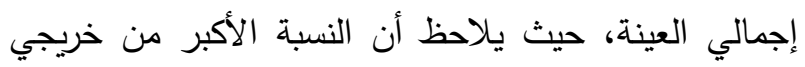

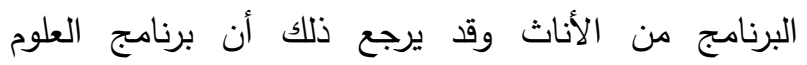

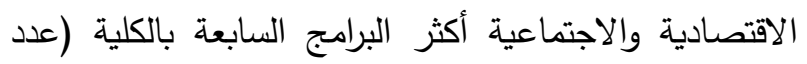
برامج الكلية V برامج متمثلة في برنامج العلوم الاقتصادية

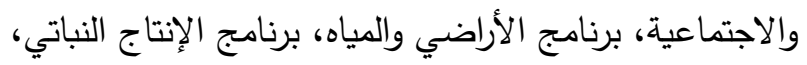

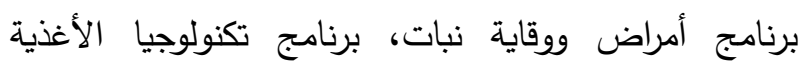
والألبان، برنامج تكنولوجيا حيوية، برنامج الإنتاج الحيواني والداجني) ملاءمة للأناث. كما تبين من متغير محل الأقامة أن عدد خريجي البرنامج

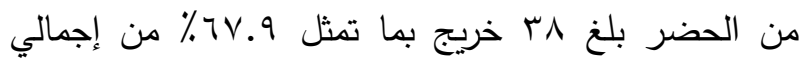

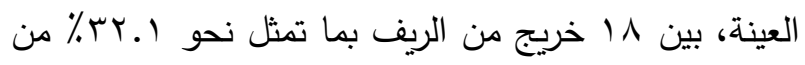

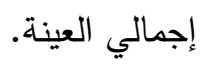

تقديرات خريج برنامج العلوم الاقتصادية والاجتماعية بكلية الزراعة جامعة عين شمس: يوضح جدول (r) وشكل(1): تقديرات خريجي برنامج العلوم الاقتصادية والاجتماعية كلية الزراعة جامعة عين

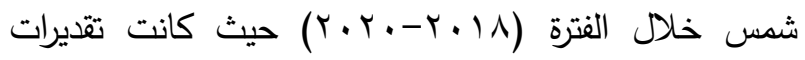

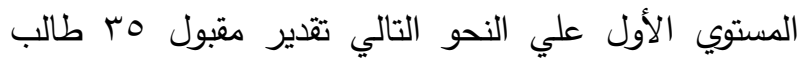

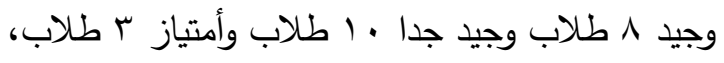

جدول 1. توصيف عينـة البحث لخريجي برنـامج العلوم

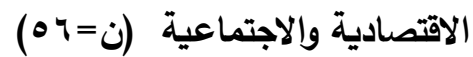

\begin{tabular}{|c|c|c|}
\hline$\%$ & ك5 & م السن \\
\hline$r .7$ & $r$ & 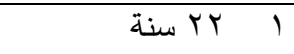 \\
\hline q. & 19 & سب سنة \\
\hline r^.T & 17 & r r \\
\hline 18.9 & 1. & 10 سنة To \\
\hline 17.1 & 9 & Tr سنة \\
\hline $1 \ldots$ & 07 & المجمـوع \\
\hline$\%$ & ك5 & التخصص الفرعي \\
\hline$T \leqslant . T$ & דו & 1 اقتصاد \\
\hline ro.v & $r$. & r اجتماع \\
\hline $1 \ldots$ & 07 & المجمـوع \\
\hline$\%$ & ك5 & النوع \\
\hline rv.o & r) & ذكر \\
\hline Tr.O & ro & أنثي \\
\hline $1 \ldots$ & 07 & المجمـوع \\
\hline$\%$ & ك5 & محل الاقامة \\
\hline $7 V .9$ & rᄉ & 1 \\
\hline r.l & 11 & r ريف \\
\hline $1 \ldots$ & 07 & المجموع \\
\hline
\end{tabular}
المصدر : جمعت وحسبت من عينة الدراسة الميدانية. أما بالنسبة لمتغير التخصص الفرعي بلغ عدد خريجي

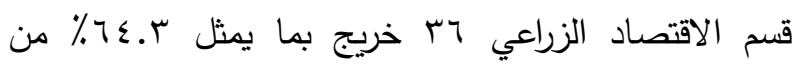

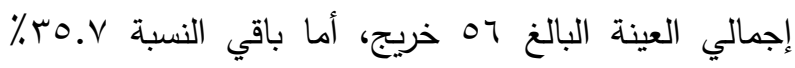

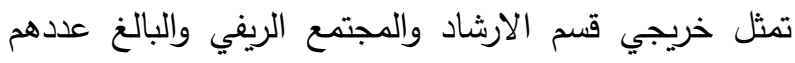

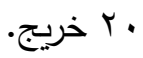
جدول r ـ تقديرات خريجي برنامج العلوم الاقتصادية والاجتماعية كلية الزراعة جامعة عين شمس للمستويات الأربعة والتقدير

\begin{tabular}{|c|c|c|c|c|}
\hline امتياز & جيد جداً & جيد & مقبول & 7 \\
\hline$r$ & 1. & $\Lambda$ & ro & الأول \\
\hline 9 & 7 & 10 & r & الثاني \\
\hline 1. & 11 & $r y$ & 9 & الثالثة \\
\hline 11 & $1 \varepsilon$ & 11 & 7 & الرابع \\
\hline V & 9 & $r r$ & IV & العام \\
\hline
\end{tabular}




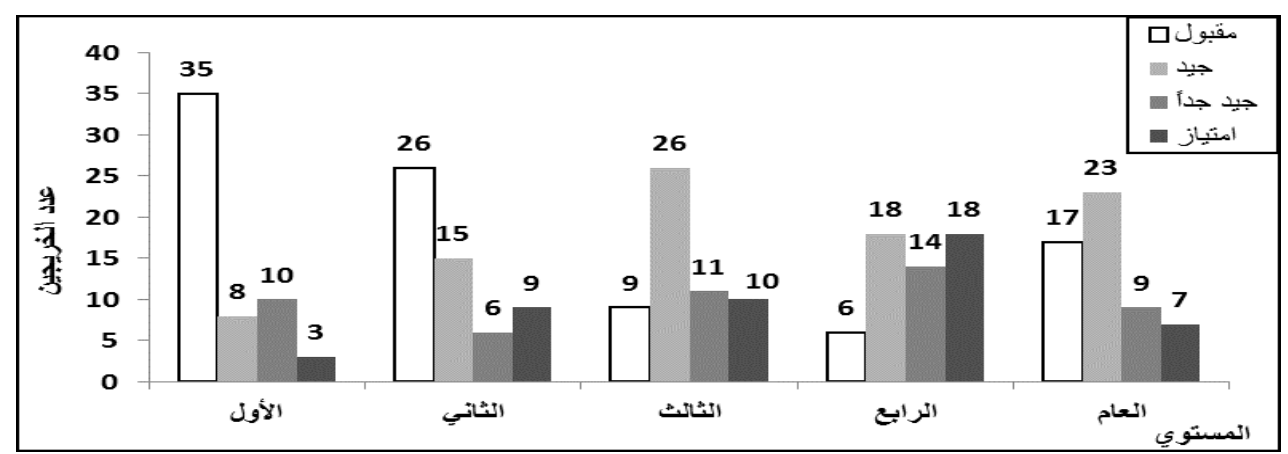

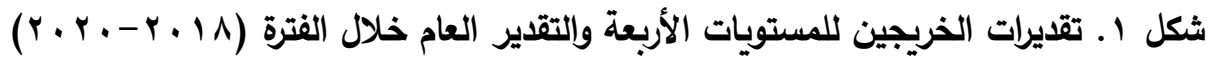

المصدر : جدول (r) بالبحث.

تـوفير فـرص عمـل للخـريج والتـدريب والتطبيقـات العمليـة

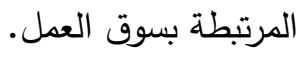

جدول r. اسباب اختيار الطلاب لبرنامج العلوم الاقتصادية والاجتماعيـة كليـة الزراعة جامعة عين شمس خـلال الفترة

$$
(r \cdot r \cdot-r \cdot 1 \Lambda)
$$

\begin{tabular}{|c|c|c|c|}
\hline الترتيب & الأهمية النسبية & العدد & السبب \\
\hline 1 & $\varepsilon \varepsilon .7$ & ro & ميول شخصية \\
\hline$\varepsilon$ & V.l & $\varepsilon$ & الأصدقاء \\
\hline r & $1 \cdot .1$ & 7 & عضو هيئة تدربس \\
\hline 0 & $0 . \varepsilon$ & r & سوق العمل \\
\hline \multirow[t]{2}{*}{$r$} & Mr.l & 11 & التخصص المتاح \\
\hline & $1 \ldots$ & 07 & الإجمالي \\
\hline
\end{tabular}

المصدر : جمعت وحسبت من عينة الدراسة الميدانية.

\section{نظرة مستقبلية للبرنامج:}

يتضح من جدول(§): نظرة مستقبلية لبرنامج العلوم

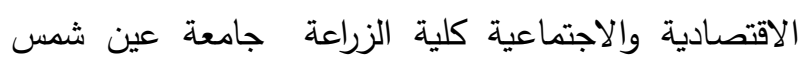

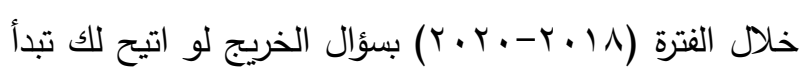
الدراسة من جديد، هل ستلتحق بالبرنامج أجاب هب خريج

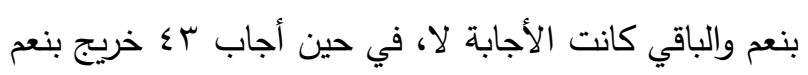
بسؤاله عن هل توصي زملاءك بالدراسة في البرنامج. وهو ما يتوافق مع البند السابق عن أسباب اختيار الطلاب لبرنامج

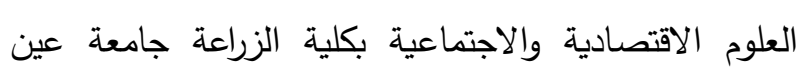

حيث يلاحظ من الجدول والثكل البياني أن تقديرات الطلاب في تحسن مستمر خلال السنوات الأربعة، حيث يتجه تقدير مقبول إلي الانخفاض في حين ترتفع باقي التقديرات، وهذه النتيجة ايجابية لصالح برنامج العلوم الاقتصادية والاجتماعية بالكلية وكذلك الطلاب.

أسباب اختيار الطلاب لبرنامج العلوم الاقتصادية والاجتماعية بكلية الزراعة جامعة عين شمس: يتبين مـن جدول (ب): اسـباب اختيـار الطـلاب لبرنـامج العلـوم الاقتصـادية والاجتماعيـة كليـة الزراعـة جامعـة عـين

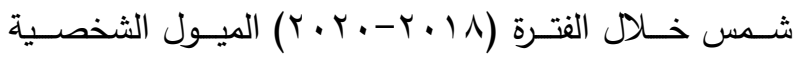
جاءت في الترتيب الأول حيث أجاب م ب خريج هذا السبب بما يمثل نحو 7. ؟ ٪ ٪ من إجمالي العينة، في حين جاء في الترتيب الثاني التخصص المطلوب بنسبة ا. بrس، وجاء في الترتيب الثالث والرابع والخامس كل من عضو هيئة تدري،

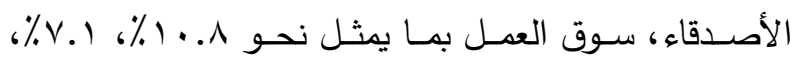
ـ. ه \% لكل منهم علي التوالي. ويتضـح لنـا أن 9.7. \% تبـين إجمـالي الأسباب مـا عدا التخصص المتاح وهي نسبة متوسطة لمدي اختيار الطلاب للألتحاق بالبرنامج، كذلك ايضا جاء سوق العمل في الترتيب الأخير ، الأمر الذي يحتاج نظرة أكثر شمولية وفعالية لتطوير للبرنـامج لجذب الطـلاب إليه ولعل مـن أهم وسـائل الجذب الهب 
جـدول \& ـ نظـرة مسـتقبلية لبرنـامج العــوم الاقتصـادية والاجتماعيـة كليـة الزراعـة جامعـة عـين شـس خـلال الفتـرة

\begin{tabular}{|c|c|c|c|c|}
\hline \multicolumn{2}{|c|}{$y$} & \multicolumn{2}{|c|}{ نعم } & الاستجابات \\
\hline نسبة & تكرار & نسبة & تكرار & رأي الخريج \\
\hline$r \cdot . \varepsilon$ & IV & 79.7 & $r q$ & \multirow{2}{*}{ لو التيح لك تبدأ الدراسة من جديد، هل ستلتحق بالبرنامج } \\
\hline rT. & $\pi$ & $v 4.1$ & $\varepsilon r$ & \\
\hline
\end{tabular}
المصدر : جمعت وحسبت من عينة الدراسة الميدانية.

الاقتصادية والاجتماعية كلية الزراعة جامعة عين شمس

\section{النتائج ومناقثتها}

وحجم العينة وعدد الخريجين الذين التحقوا بسوق العمل خلال

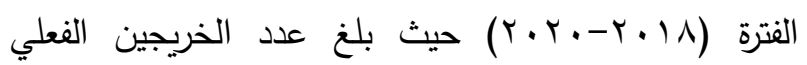

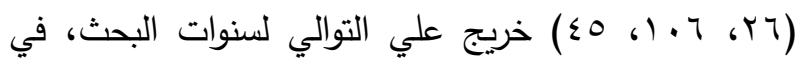

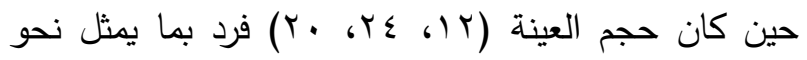

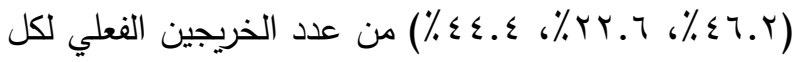

- معدل البطالة لخريجي برنامج العلوم الاقتصادية والاجتماعية بكلية الزراعة جامعة عين شمس: خريجي برنامج العلوم الاقتصادية والاجتماعية الذين التحقوا

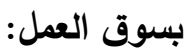

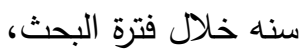
يبين جدول (0) وشكل(r): عدد خريجي برنامج العلوم جدول ه. عدد خريجي برنامج العلوم الاقتصادية والاجتماعية كلية الزراعة جامعة عين شمس وحجم العينة وعدد الخريجين

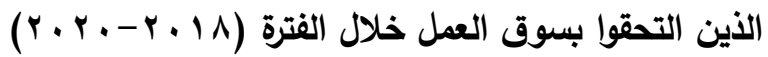

\begin{tabular}{|c|c|c|c|c|c|}
\hline \multicolumn{2}{|c|}{ سوق العمل } & \multicolumn{2}{|l|}{ العينة } & \multirow{2}{*}{ عدد الخريجين الفعلي } & \multirow[b]{2}{*}{ السنوات } \\
\hline$\%$ & عدد & \% حجم العينة إلى عدد الخربجين & الحجم & & \\
\hline $1 . . v$ & 7 & $\leqslant 7.10$ & IT & rT & $r .11$ \\
\hline $1 \leqslant . r$ & $\wedge$ & TY.TE & $r \varepsilon$ & 1.7 & $r .19$ \\
\hline YА. $T$ & 17 & oV.1 \{ & $r$. & ro & $r \cdot r$. \\
\hline$\varepsilon 7 . \leqslant$ & r & - & - & - & لا يعمل \\
\hline $1 \ldots$ & 07 & O. & 07 & $17 \mathrm{~V}$ & الإجمالى \\
\hline
\end{tabular}

المصدر : جمعت وحسبت من سجلات شئون الخريجين بالكلية ونتائج عينة البحث.

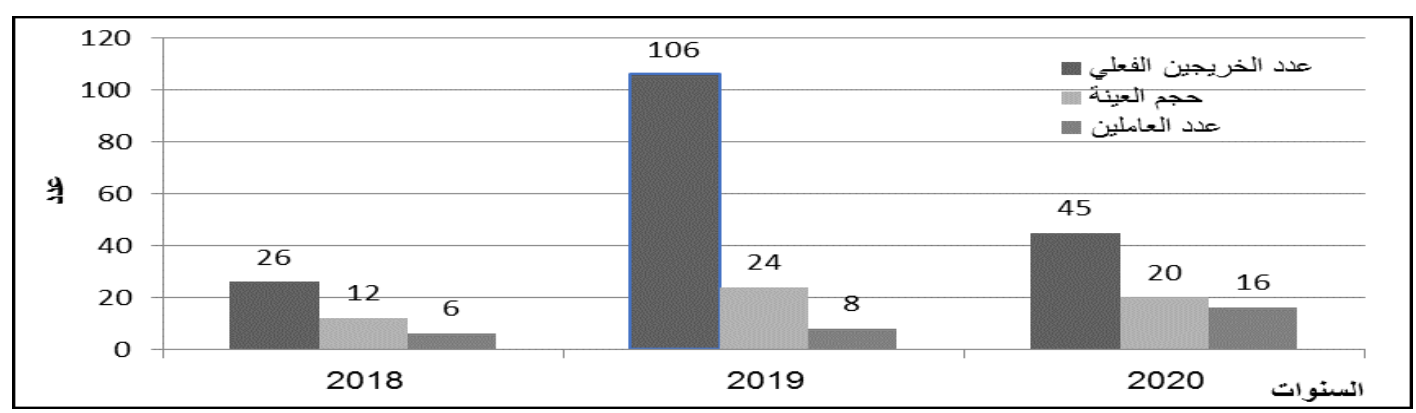

شكل r . عدد خريجي برنامج العلوم الاقتصادية والاجتماعية كلية الزراعة جامعة عين شمس وحجم العينة وعدد الخربجين

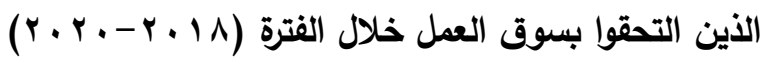




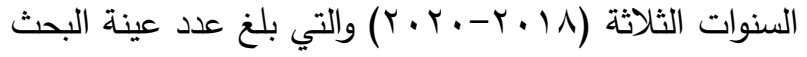
فيها جه خريج (قوة عاملة) وعدد العاطلين جr عاطل بناتج معدل بطالة حوالي ؟.0٪ ٪، وهي نسبة كبيرة جدا لا يستهان بها.

r - تحليل درجة رضا الخريج عن برنامج العلوم الاقتصادية والاجتماعية

أولاً: درجة رضا الخريجين عن المقررات الدراسية ومدي ارتباطها باحتياجات سوق العمل:

يتضح من جدول(V): المتوسط المرجح والنسبة التقديرية لدرجة رضا الخريجين عن المقررات الدراسية ومدي ارتباطها باحتياجات سوق العمل متوسط حيث بلغت النسبة الكلية نحو r.4\%٪ حيث جاء في الترتيب الأول "المواد الدراسية

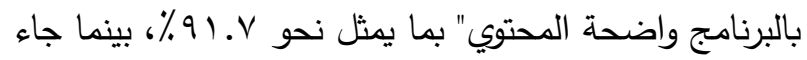
في الترتيب الثاني "المواد الدراسية بالبرنامج لها علاقة مباشرة بسوق العمل" يمثل نحو 9.1\%٪، في حين جاء في الترتيب الثالث "المواد الدراسية بالبرنامج تتمي المهارات المختلفة لمواجهة سوق العمل" بما يمثل r.^^٪، في حين جاء في الترتيب الرابع "الاستفادة من المقررات عالية" بما يمثل نحو

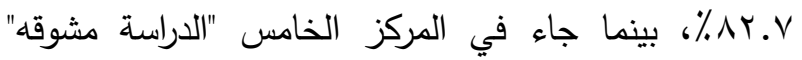
حيث بلغ نحو 1.1\%٪، في حين جاء في الترتيب السادس والسابع والثامن والتاسع والعاشر كل من "تتوافر معارف ومعلومات حديثة في المقررات التي تم دراستها" ، "ينبغي إلغاء بعض المقررات لعدم ملاءمتها مع سوق العمل"، "ينبغي اضافة بعض المقرخات تماشياً مع سوق العمل" و"يجب التعمق في دراسة بعض المقررات لخدمة سوق العمل"، "ينبغي تغيير بعض المقررات لتماشي مع سوق العمل" بنسبة

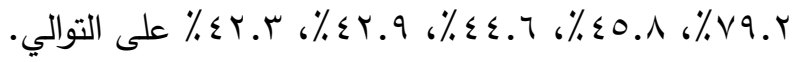

في حين تبين ايضا من الجدول أن عدد الخريجين الذين التحقوا بسوق العمل بلغ (ד، ^، 1 (1) عامل علي التوالي، حيث بلغ إجمالي عدد العاطلين خلال فترة الدراسة بr عاطل من إجمالي 07 خريج. تحديد معدل البطالة لخريجي برنامج العلوم الاقتصادية والاجتماعية بكلية الزراعة جامعة عين شمس: تقاس البطالة في العادة بما يسمى بمعدل البطالة "Unemployment Rate" (المتعطلين) من القوة العاملة إلى إجمالي قوة العمل. ويمكن حساب معدل البطالة من خلال القانون التالي: معدل البطالة = عدد العاطلين عن العمل ٪ إجمالي القوة

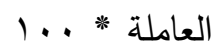

والقوة العاملة من السكان هم جميع القادرين والراغبين في العمل .ويتم في العادة استبعاد الأطفال دون سن 10 سنة، وكبار السن، والمتقاعدين والعاجزين، وربات البيوت غير

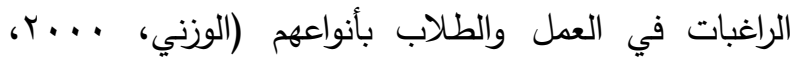
صبr). وهنا نشير إلي أن القوة العاملة تمثل خريجي برنامج العلوم الاقتصادية والاجتماعية بكلية الزراعة جامعة عين شمس.

حيث يتضح من جدول (†): معدل البطالة لخريجي برنامج العلوم الاقتصادية والاجتماعية كلية الزراعة جامعة

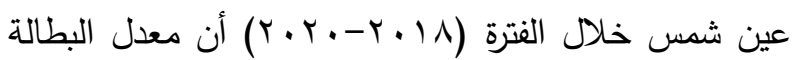

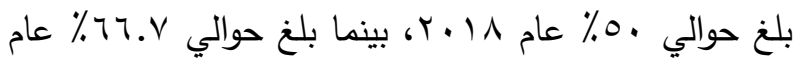

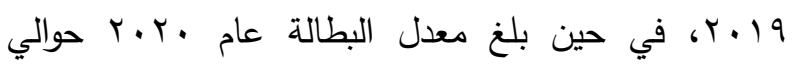

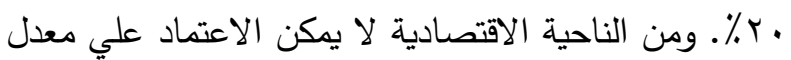
البطالة في كل عام علي حده ويرجع ذلك في أنه ليس شرطاً أن يكون عدد العاملين والعاطلين في سنة معينة هو نتاج عدد الخريجين في نفس السنة وإنما قد يكون لسنوات سابقة للتخرج، وبالتالي يفضل الاعتماد علي معدل البطالة لإجمالي 


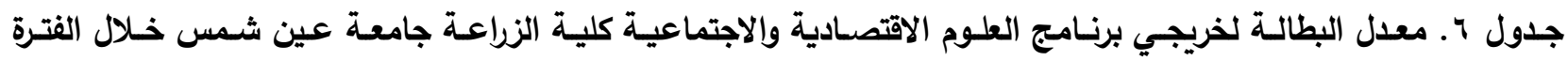

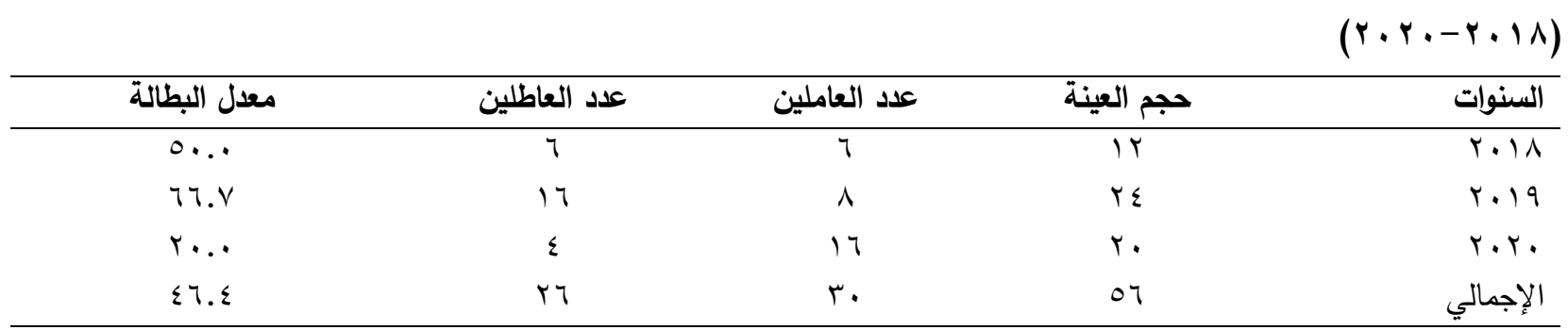

المصدر : جمعت وحسبت من جدول (0) بالبحث.

جدول v. المتوسط المرجح والنسبة التقديرية لارجة رضا الخريجين عن المقررات الدراسية ومدي ارتباطها باحتياجات سوق

\begin{tabular}{|c|c|c|c|c|c|c|c|c|}
\hline \multirow[b]{2}{*}{ الترتيب } & \multirow{2}{*}{ التقديرية } & \multirow[b]{2}{*}{ المرجح } & \multirow[b]{2}{*}{ 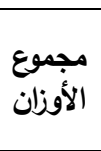 } & \multicolumn{3}{|c|}{ الاستجابات (ن= ه ه) } & \multirow[b]{2}{*}{ 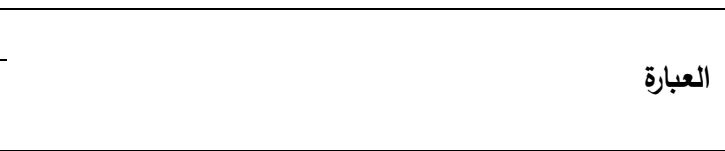 } & \multirow[b]{2}{*}{ رقب } \\
\hline & & & & راضير & حل ما & راضي & & \\
\hline$r$ & ᄉ . .9 & Y.TI & $1 \leq 7$ & $\varepsilon$ & $1 \leq$ & rᄉ & المواد الدراسية بالبرنامج لها علاقة مباشرة بسوق العمل & 1 \\
\hline 1 & $91 . \vee$ & r.Vo & $10 \leqslant$ & r & $\wedge$ & $\leq 0$ & المواد الدراسية بالبرنامج واضحة الدحتوي & r \\
\hline$r$ & Ar.r & r.०. & $1 \leqslant$. & $\checkmark$ & $1 \leq$ & ro & العمل الدراسية بالبرنامج تتمي المهارات المختلفة لمواجهة سوق & $\mu$ \\
\hline 0 & Ar.l & Y. $\leqslant \uparrow$ & Ir人 & $\varepsilon$ & rr & r. & الدراسة مشوقه & $\varepsilon$ \\
\hline$\varepsilon$ & Ar.V & r. ¿^ & 149 & r & ro & rq & الاستفادة من المقررات عالية & $\circ$ \\
\hline 9 & $\leqslant r .9$ & 1.49 & Vr & 1 & $1 \leq$ & $\varepsilon$ & يجب التعمق في دراسة بعض المقررات لخدمة سوق العمل & 7 \\
\hline 1. & $\leq r . r$ & $1 . r v$ & (1) & r & 9 & $\varepsilon \varepsilon$ & ينبغي تغيير بعض الامقررات لتتماشي مع سوق نالعمل & $v$ \\
\hline$\checkmark$ & $\leq 0.1$ & $1 . r \Lambda$ & $\checkmark v$ & 7 & 9 & $\varepsilon$ & ينبغي إلغاء بعض الدقررات لعدم ملاءهتها مع سوق العمل & $\wedge$ \\
\hline$\wedge$ & $\leqslant \varepsilon .7$ & $1 . r \varepsilon$ & vo & $\varepsilon$ & 11 & $\leqslant$ & ينبغي اضافة بعض المقررات تماشياً مع سوق العمل & 9 \\
\hline 1 & V৭. & r.r人 & שr & $1 \cdot$ & 10 & r & تتوافر معارف ومعلومات حديثة في الدقررات التي تم دراستها & $1 \cdot$ \\
\hline توسط & Tی. & r.. $\varepsilon$ & $11 \leq 0$ & $\leqslant \varepsilon$ & $1 \leq 1$ & rvo & المتغير ككل & مجموع \\
\hline
\end{tabular}

المصدر : جمعت وحسبت من عينة الدراسة الميدانية.

جودة أداء عضـو هيئة التـدريس مـن خـلال عمليـات التقويخ والتحسين والتطوير التي تمارس بشكل مستمر ، الأمر الذي

ينعكس إيجاباً على جودة المؤسسة التعليمية ومخرجاتها. ويتضح من جدول(^): المتوسط المرجح والنسبة التقديرية

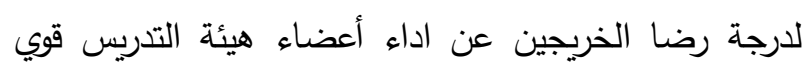
حيث بلغت النسبة الكلية نحو 19.1٪، حيث جاء في الترتيب الأول "العلاقة متبادلة بين الاستاذ والطالب في مجال الدراسة" بما يمثل نحو 0.؟ ٪٪، بينما جاء في الترتيب الثاني
ثانياً: درجة رضا الخريجين عن اداء اعضاء هيئة التدريب: عضـو هيئسة التـدريس أحـــ أهـم العناصـر التـي تتظـافر

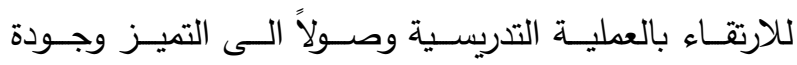
المخرجات، وخاصـة في ظل التـافس الثديد بين مؤسسات التعليم العـالي في عصـر العولمـة، الذي يشهـ ثورة معرفيـة وتكنولوجيـة هائلــة، وتتوعـاً فـي أسـاليب التـدريس الحديثـة باسـتخدام تكنولوجيـا المعلومـات والاتصـالات. لـذلك أصـبح لزاماً على مؤسسات التعليم العالي تهيئة كل الظروف لتحسين لكين 
"قدرة الأستاذ علي الثرح وايضاح المعلومات وتقديم الدعم الترتيب العاشر والعاشر مكرر "استخدام الاستاذ للتقنيات الحديثة" و"الدرجات التي يحصل عليها الطلاب لا تعبر عن

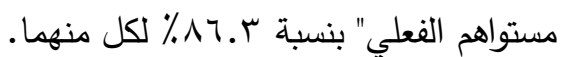
ثالثاً: درجة رضا الخريجين عن مستوي أداء الخدمات بالكلية: يتضح من جدول(9): المتوسط المرجح والنسبة التقديرية لارجة رضا الخريجين عن مستوي أداء الخدمات بالكلية

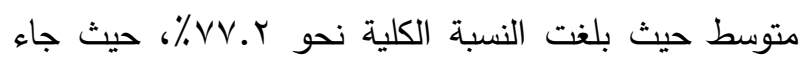
في الترتيب الأول "إمكانية الحصول على الإرشاد والتوجيه"

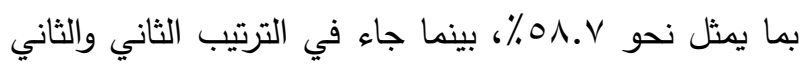
مكرر كل من "الخدمات المقدمة من المكتبة"،
والارشاد الاكاديمي" يمثل نحو r.9.9\%، في حين جاء في الترتيب الثالث "التفاعل المتبادل بين الاستاذ والطالب" بما يمثل r.r.\%، في حين جاء في الترتيب الرابع " فرصة التفاعل مع اعضاء الهيئة التدريسية خارج القاعات التدريسية" بما يمثل نحو V. 19٪، بينما جاء في المركز الخامس "وضع الامتحان عادل وغير متحيز" حيث بلغ نحو 0. .9 ٪، في حين جاء في الترتيب السادس والسادس مكرر "اهتمام الاستاذ بأراء الطلاب ورد الفعل" و "العلاقة جيدة بين الاستاذ والطالب

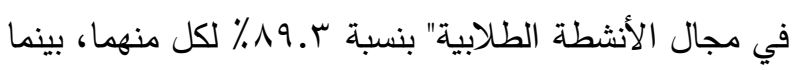
جاء في الترتيب الثامن والثامن مكرر "إلمام الاستاذ بالتطبيقات العلمية" و"معرفة الأساس والقواعد التي يقيم اداء

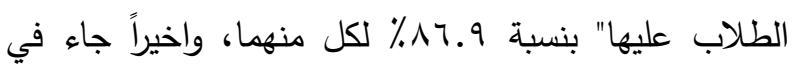

جدول ^. المتوسط المرجح والنسبة التقديرية لارجة رضا الخريجين عن أداء اعضاء هيئة التدريس

\begin{tabular}{|c|c|c|c|c|c|c|c|c|}
\hline \multirow[b]{2}{*}{ الترتيب } & \multirow{2}{*}{ التقديرية } & \multirow{2}{*}{ المترجط } & \multirow[b]{2}{*}{ الأوزان } & \multicolumn{3}{|c|}{ الاستجابات (ن= †ه) } & \multirow[b]{2}{*}{ العبارة } & \multirow{2}{*}{ 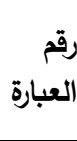 } \\
\hline & & & & 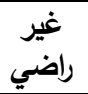 & حإلي & راضي & & \\
\hline r & 94.9 & r.vq & 107 & 1 & 1. & $\varepsilon 0$ & قالارشاد الأكاديمي علي الثرح وايضـاح المعلومـات وتقديم الــعم & 1 \\
\hline 1. & ᄉ५. & r.09 & $1 \leqslant 0$ & 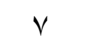 & 9 & $\varepsilon$. & استخدام الاستاذ للتقتيات الحديثة & r \\
\hline r & 94.4 & r.VV & 100 & r & 9 & $\leqslant 0$ & التفاعل المتبادل بين الاستاذ والطالب & r \\
\hline$\wedge$ & ᄉ . .9 & r.T & $1 \leqslant 7$ & 0 & ir & rq & إلمام الاستاذ بالتطبيقات العلمية & $\varepsilon$ \\
\hline 1 & ^९.५ & r.१^ & 10 & r & $1 \leqslant$ & $\varepsilon$ & اهتمام الاستاذ بأراء الطلاب ورد الفعل & $\circ$ \\
\hline 1 & 94.0 & Y.A. & $10 \mathrm{~V}$ & 1 & 9 & $\leq 7$ & العلاقة متبادلة بين الاستاذ والطالب في مجال الدراسة & 1 \\
\hline 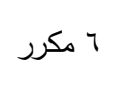 & ^৭. & T.T^ & 10 & $\varepsilon$ & 1. & $\varepsilon r$ & 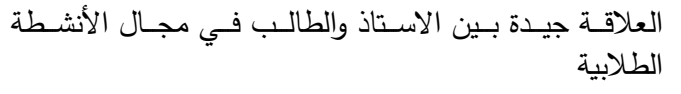 & V \\
\hline$\circ$ & $9 . .0$ & r.VI & lor & 0 & 7 & «o & وضع الامتحان عادل وغير متحيز & $\wedge$ \\
\hline • ا مكرر & ᄉ५. & r.09 & $1 \leqslant 0$ & rᄉ & ir & 0 & الفعلي & 9 \\
\hline 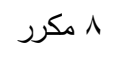 & 17.9 & r.T) & $1 \leqslant 7$ & $\varepsilon$ & $1 \varepsilon$ & rی & معرفة الأساس والقواعد التي يقيم اداء الطلاب عليها & 1. \\
\hline$\varepsilon$ & $91 . V$ & r.vo & $10 \leqslant$ & r & $1 \cdot$ & $\varepsilon \varepsilon$ & فرصـة التفاعل مـع اعضــاء الهيئة التدريسية خـارج القاعـات & 11 \\
\hline \multicolumn{2}{|c|}{ 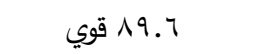 } & r.79 & 1707 & rᄉ & 117 & $\leqslant \pi r$ & \multicolumn{2}{|c|}{ مجموع المتغير ككل } \\
\hline
\end{tabular}


جدول 9.

\begin{tabular}{|c|c|c|c|c|c|c|c|c|}
\hline \multirow[b]{2}{*}{ الترتيب } & \multirow{2}{*}{ التقديربة } & \multirow{2}{*}{ المرجح } & \multirow{2}{*}{ الأوزان } & \multicolumn{3}{|c|}{ الاستجابات (ن= †ه) } & \multirow[b]{2}{*}{ 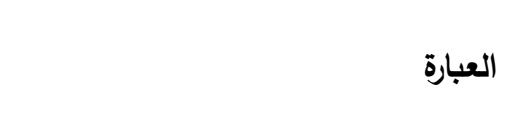 } & \multirow{2}{*}{ العبارة } \\
\hline & & & & راضير & إلي حـا & 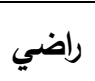 & & \\
\hline 1. & $\vee r . \wedge$ & Y.YI & ITE & Ir & r. & $r \varepsilon$ & البنية التحتية للكلية & 1 \\
\hline$\checkmark$ & $\vee \wedge .7$ & T.ru & ITr & $\checkmark$ & rt & rV & 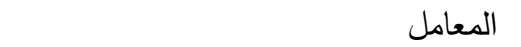 & r \\
\hline r & NT.r & Y.o. & $1 \leq$. & 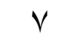 & $1 \varepsilon$ & ro & الخدمات المقدمة من المكتبة & r \\
\hline 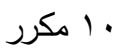 & $\vee r . \Lambda$ & T.MI & IrE & 11 & rr & rt & الانشطة الطلابية المختلفة للكلية & $\varepsilon$ \\
\hline 9 & $V \varepsilon . \varepsilon$ & t.rt & Iro & 9 & ro & rt & الدورات التدريبية & ○ \\
\hline$\wedge$ & $\vee \vee . \varepsilon$ & t.rt & 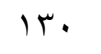 & 1. & 11 & rA & المؤتمرات والندوات وورش العمل & 7 \\
\hline 7 & V৭. & T.r人 & חזו & $\wedge$ & 19 & rq & التدريب الميداني & $\vee$ \\
\hline r r اكرر & Nr.r & Y.O. & $1 \leq$ & 7 & 17 & $r \leq$ & وجود مرشدين أُكاديميين & $\wedge$ \\
\hline 1 & ^०.V & Y.OV & $1 \leq \varepsilon$ & $\varepsilon$ & 17 & r & إمكانية الحصول على الإرشاد والتوجيه & 9 \\
\hline 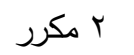 & ( & r.o. & $1 \leq$ & 7 & 17 & $r \varepsilon$ & جودة الإرشاد الأكاديمي بشكل عام & 1. \\
\hline ir & 71.0 & r...O & 110 & 11 & iv & r) & الخدمات الصحية المقدمة بعيادة الجامعة & 11 \\
\hline 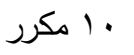 & Vr.^ & T.Y & $1 Y \varepsilon$ & ir & $r \cdot$ & $r \varepsilon$ & الخدمات المقدمة من قبل الطاقم الإداري & ir \\
\hline $1 \varepsilon$ & $7 \varepsilon . \Gamma$ & 1.94 & $1 \cdot 1$ & $r \varepsilon$ & ir & $r \cdot$ & إمكانية الدخول لثبكة الإنترنت & Ir \\
\hline 0 & $\wedge .$. & T.ET & 147 & 1. & ir & $r \varepsilon$ & توفر خدمات النسخ والتصوير & $1 \leq$ \\
\hline \multicolumn{2}{|c|}{ متوسط VV.Y } & t.rt & 1110 & $1 \leq \varepsilon$ & $r \leq q$ & (q) & \multicolumn{2}{|c|}{ مجموع المتغير ككل } \\
\hline
\end{tabular}

المصدر : جمعت وحسبت من عينة الدراسة الميدانية.

رابعاً: احتياجات سوق العمل: (درجة رضا الخريجين عن مستوي المعارف والمهارات والتدريب بالبرنامج)

يمثل سوق العمل جانبين هما جانب العرض والذي يمثل

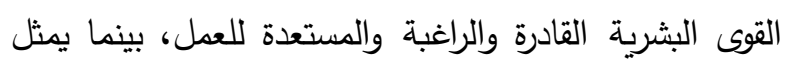
جانب الطلب المنظمات التي تحدد الأماكن الثاغرة فيها وشروط شغل هذه الأماكن، وقد يتمثل سوق العمل في المكان أو

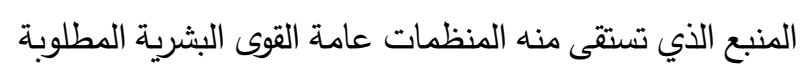

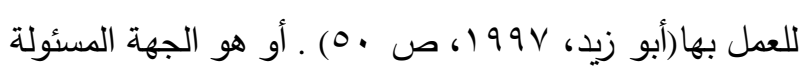
عن توزيع العمالة على الوظائف المتاحة وفقاا للمستويات المهارية لكل عامل، مع التسيق بين قرارات التوظيف

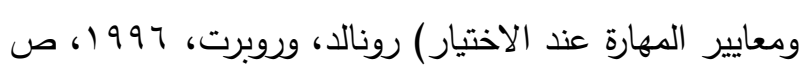

ويمكن النظر إلى سوق العمل إجرائياً بأنه المجتمع الذي

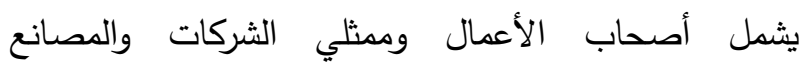
والمؤسسات بالإضافة إلى الأفراد الباحثين عن وظائف في المجتمع المصري سواء حديثي التخرج أو ذوي الخبرة السابقة،
"وجود مرشدين أكاديميين" و"جودة الإرشاد الأكاديمي بثكل عام" يمثل نحو س.بر٪ لكل منهم، في حين جاء في الترتيب الخامس "توفر خدمات النسخ والتصوير" بما يمثل 1^٪، في حين جاء في الترتيب السادس "التدريب الميداني" بما يمثل نحو Y.Y.\%، بينما جاء في المركز السابع

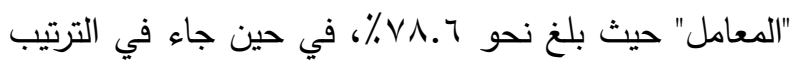
الثامن "المؤتمرات والندوات وورش العمل" بما يمثل نحو

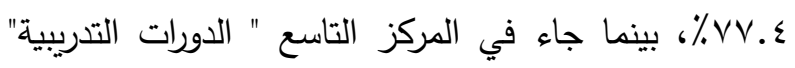
حيث بلغ نحو ع. ع٪\%، بينما جاء في الترتيب العاشر

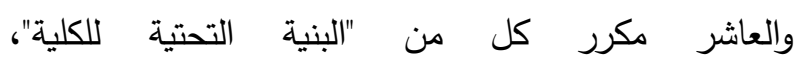
"الانشطة الطلابية المختلفة للكلية" و"الخدمات المقدمة من من لعرد قبل الطاقم الإداري" بنسبة ^.ب٪\% لكل منهم، كما جاء في الترتيب الثالث عشر والأخير كل من "الخدمات الصحية المقدمة بعيادة الجامعة" و"إمكانية الدخول لشبكة الإنترنت"

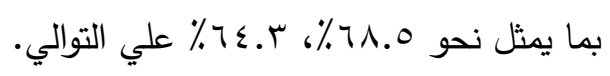




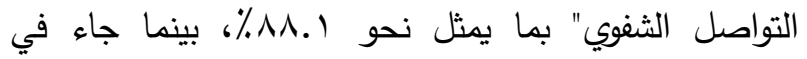
الترتيب الثاني "التدريب على التواصل المكتوب" يمثل نحو r.^^٪، في حين جاء في الترتيب الثالث والثالث مكرر "درجة معرفتك بالمعارف والمهارات والكفايات المطلوب منك إتقانها في نهاية دراستك للبرنامج" و"تتمية مهارات العمل

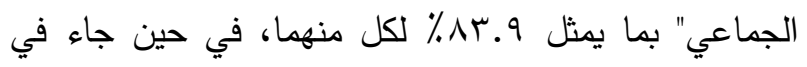
الترتيب الخامس "تتمية مهارات التفكير الناقد والتحليل" بما يمثل نحو ه.بر٪، في حين جاء في الترتيب السادس والسادس مكرر "تتمية المهارات الحياتية (تحديد الأولويات, إدارة الوقت)" و "التدريب على تطبيقات الحاسوب الضرورية " بنسبة ر.AY\% لكل منهما، بينما جاء في الترتيب الثامن والتاسع والأخير كل من "تتمية مهارات القيادة"، "توافر الدورات التدريبية في مجالات متتوعة ذات العلاقة بسوق

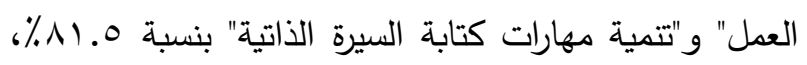

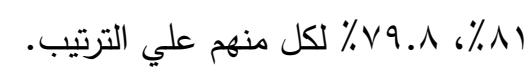

مع مراعاة أن هذا المجتمع تتحكم فيه عوامل العرض والطلب فكلما زاد الطلب زادت نسبة فرصة العمل وقلة البطالة والعكس فرس بالعكس. كما يعرف احتياجات سوق العمل بأنه مجموعة من المعارف والمفاهيم والقدرات والمهارات الواجب توافرها لدى الخريج طبقا لمعايير الجودة الثاملة المعيارية المقننة لينجح في تلبية مطالب سوق العمل المتقدم تكنولوجيا. (غادة عبد

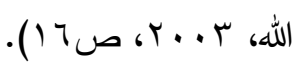
ويقصد بها إجرائياً مجموعة المعارف والمفاهيم والمها رات الأدائية التي ينبغي على الخريج الاتصاف بها في ضوء متطلبات المجتمع. حيث يتضح من جدول (· (1): المتوسط المرجح والنسبة التقديرية لدرجة رضا الخريجين عن مستوي تطوير المعارف والمهارات والتدريب بالبرنامج قوي حيث بلغت النسبة الكلية

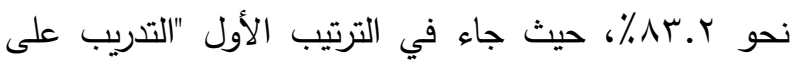
جدول ـ 1. المتوسط المـرجح والنسبة التقديريـة لارجـة رضـا الخريجين عن مستوي تطوير المعـارف والمهـارات والتـدربب

بالبرنامـج

\begin{tabular}{|c|c|c|c|c|c|c|c|c|}
\hline \multirow[b]{2}{*}{ الترتيب } & \multirow[b]{2}{*}{ التقديرية } & \multirow[b]{2}{*}{ المرجوسط } & \multirow[b]{2}{*}{ ألأجمان } & \multicolumn{3}{|c|}{ الاستجابات (ن= ^ه) } & \multirow[b]{2}{*}{ العبارة } & \multirow[b]{2}{*}{ رقبح } \\
\hline & & & & غاضير & إلي حـ & راضي & & \\
\hline$r$ & งr.q & r.OY & $1 \leqslant 1$ & 0 & iv & $r \varepsilon$ & 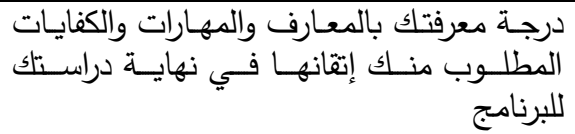 & 1 \\
\hline 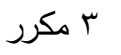 & ᄉr.q & r.or & $1 \leqslant 1$ & $\varepsilon$ & 19 & 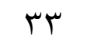 & تتمية مهارات العمل الجماعي & r \\
\hline 7 & $\wedge r . l$ & Y.乏T & Ir人 & $\varepsilon$ & r & r. & تلتمية المهارات الحياتية (تحديد الأولويات, إدارة & $r$ \\
\hline$\wedge$ & 11.0 & r. $\leqslant 0$ & ITV & 0 & r) & $r$. & تتمية مهارات القيادة & $\varepsilon$ \\
\hline 0 & (ז.r & r.o. & $1 \leq$ & $\varepsilon$ & $r \cdot$ & rt & تتمية مهارات التفكير الناقد والتحليل & 0 \\
\hline 1 & $\wedge \wedge .1$ & T.Tะ & $1 \leq \Lambda$ & r & 17 & ґᄉ & التدريب على التواصل الشفوي & 7 \\
\hline r & ᄉт. & r.09 & $1 \leqslant 0$ & r & 19 & ro & التدريب على التواصل المكتوب & $\checkmark$ \\
\hline 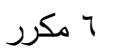 & Ar.l & Y. $\Sigma \uparrow$ & Irk & $\varepsilon$ & 19 & rt & التدريب على تطبيقات الحاسوب الضرورية & $\wedge$ \\
\hline 1. & $\vee 9.1$ & r.rq & $1 \pi \varepsilon$ & v & $r \cdot$ & rq & تتمية مهارات كتابة السيرة الذاتية & 9 \\
\hline 9 & $\wedge .$. & $r . \varepsilon r$ & 1ry & 0 & rr & rq & ذـات العلاقة بسوق التّربيـة في مجـالات متتوعـة & $1 \cdot$ \\
\hline \multicolumn{2}{|c|}{ r.rی قوي } & Y.0. & 11491 & $\varepsilon r$ & 190 & rrt & \multicolumn{2}{|c|}{ مجموع المتغير ككل } \\
\hline
\end{tabular}


التعليم والتعلم وإعداد القوى العاملة وفقا للتغيرات الحادثة في

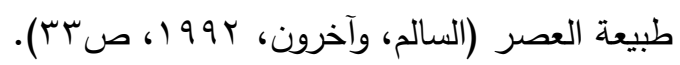
حيث يتضح من جدول (1) (1): المتوسط المرجح والنسبة التقديرية لدرجة رضا الخريجين عن أداء سوق العمل اتجاههم متوسط حيث بلغت النسبة الكلية نحو 0.0 \%٪، حيث جاء

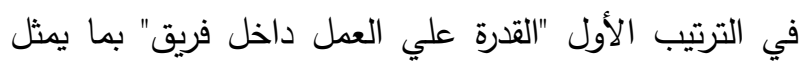

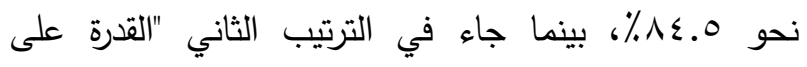

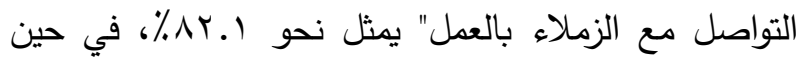
جاء في الترتيب الثالث "القدرة علي التواصل مع الزملاء بالعمل" بما يمثل ایی٪، في حين جاء في الترتيب الرابع "التشجيع علي التعلم الذاتي" بما يمثل نحو ؟ ـ. ــ٪، في حين جاء في الترتيب الخامس "القدرة علي اجتياز المقابلات

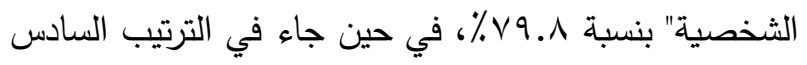

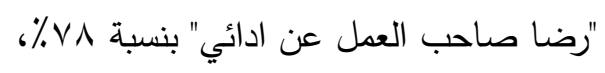

خامساً: أداء سوق العمل اتجاه الخربجين: (درجة رضا الخريجين عن أداء سوق العمل (تجاههم)

التغير في الهياكل والبنى الاقتصادية أدى إلى تحولات أخرى سريعة في البنى الوظيفية أو المهنية بحيث ازدادت الحاجة إلى عمالة ذات مستويات وظيفية عالية تصحبها بالضرورة مستويات تعليمية عالية، وهذا الأمر يعني أن المستوى المهاري والعلمي لقوة العمل يرتبط في الأساس بوجود

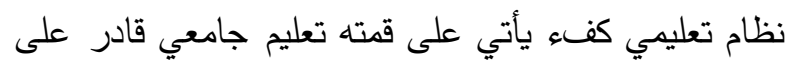
توفير القوي البشرية اللازمة لمواجهة التحديات الاقتصادية والتكنولوجية التي تؤدي بدورها إلى تغيرات سريعة ومتلاحقة في حجم ونوعية سوق العمل، ومثل هذه التغيرات تفرض مطالبها على التعليم العالي وتجعله أكثر حاجة لمواكبة التغيرات التكنولوجية في العمل والحياة واستيعاب الانفجار المعرفي، لهوله وحسن استخدام تكنولوجيا المعلومات الجديدة في عمليات

جدول 11 اـ المتوسط المرجح والنسبة التقديرية لارجة رضا الخربجين عن أداء سوق العمل اتجاههم

\begin{tabular}{|c|c|c|c|c|c|c|c|c|}
\hline \multirow[b]{2}{*}{ الترتيب } & \multirow{2}{*}{ التقديرية } & \multirow{2}{*}{ المرجح } & \multirow{2}{*}{ الأْوزلَ } & \multicolumn{3}{|c|}{ 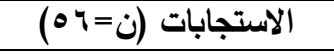 } & \multirow[b]{2}{*}{ 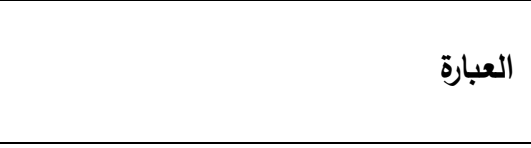 } & \multirow{2}{*}{ العبارة } \\
\hline & & & & راضير & مالي حد & راضي & & \\
\hline$\wedge$ & $\vee \mu . \Lambda$ & r.Y. & $1 T \varepsilon$ & $1 \pi$ & 11 & ro & 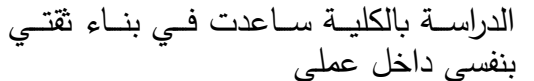 & 1 \\
\hline r & $\wedge 1$. & r. $\leqslant$ T & 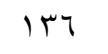 & 9 & $1 \varepsilon$ & r & القدرة" علي التواصلّ مع الزملاء بالعمل & r \\
\hline 1 & $\wedge \varepsilon .0$ & Y.0乏 & $1 \leqslant r$ & 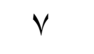 & ir & $r v$ & القدرة علي العمل داخل فريق & r \\
\hline$\varepsilon$ & $\wedge \cdot . \varepsilon$ & r.乏) & 1 To & $1 \cdot$ & ir & Tr & التشجيع علي التعلم الذاتي & $\varepsilon$ \\
\hline 9 & $V Y . T$ & r.11 & Irt & Ir & rt & rr & تعلمتها مندريب الكلية الاخرين علي المهارات التي & 0 \\
\hline 11 & 71.0 & r... & 110 & r) & iv & 11 & مجال العمل ليس له علاقة بالتخصص & 7 \\
\hline v & V५. & r. rq & $1 \mu_{1}$ & 11 & 11 & rV & يوجد تواصل مستمر مع البرنامج & v \\
\hline ir & $T V . r$ & r.. & 114 & rr & ir & r) & صعوبة الحصول علي وظيفة بعد التخرج & $\wedge$ \\
\hline 1. & 79.7 & r.. 9 & $11 \mathrm{~V}$ & 19 & ir & $r \varepsilon$ & حصولي علي راتب جيد من عملي & 9 \\
\hline 7 & $\vee \wedge$. & T.r & 141 & ir & ir & 少 & رضا صاحب العمل عن ادائي & $1 \cdot$ \\
\hline r & Ar.l & Y. ¿T & Ir人 & 9 & ir & ro & القدرة على التواصل مع الزملاء بالعمل & 11 \\
\hline 0 & $\vee 9.1$ & r.rq & $1 \pi \varepsilon$ & $1 \cdot$ & $1 \varepsilon$ & re & قدرتي إجتياز المقابلات الثخصية & ir \\
\hline مكرر 11 & 71.0 & r... & 110 & $r \cdot$ & \% & rr & الحصول علي وظيفة تتاسب درجتي & ir \\
\hline \multicolumn{2}{|c|}{ V0.0 منوسط V م } & T. YV & 170 & $|v|$ & $19 r$ & r7o & \multicolumn{2}{|c|}{ مجموع المتغير ككل } \\
\hline
\end{tabular}


المقررات الدراسية ومدي ارتباطهـا باحتياجـات سوق العمل دونل

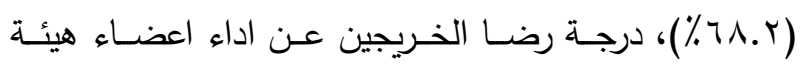

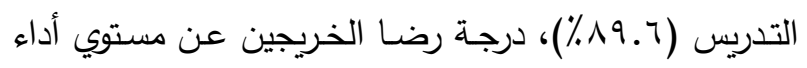

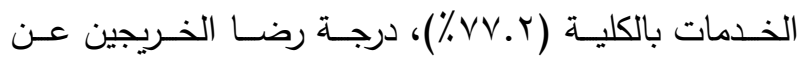

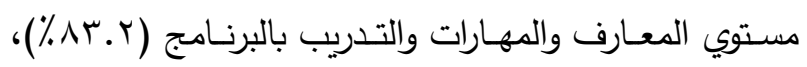

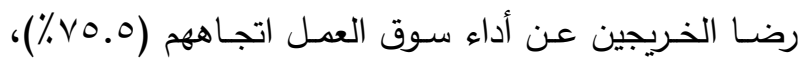

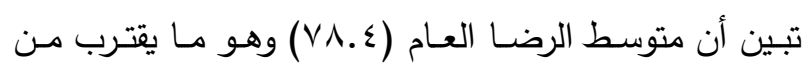

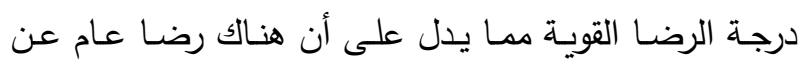

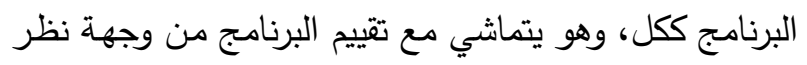

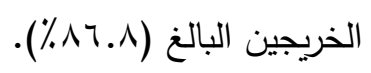

r- تقييم البرنامج من خلال ما قدمته الكلية من وجهة نظر

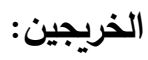

حيث يتضح من جدول (r ()): المتوسط المرجح والنسبة التقديرية لتقييم البرنامج من خلال ما قدمته الكلية للخريجين

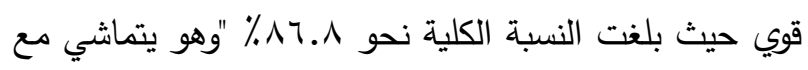

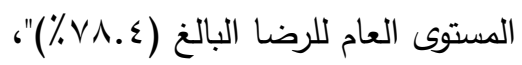

بينما جاء في الترتيب السابع والثامن والتاسع والعاشر

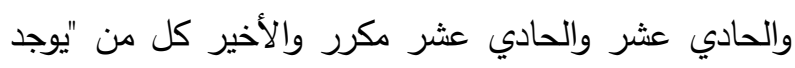

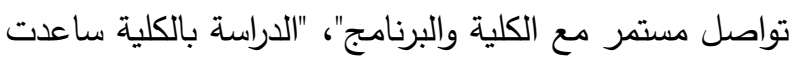
في بناء ثقتي بنفسي داخل عملي"، "قدت بتدريب الاخرين

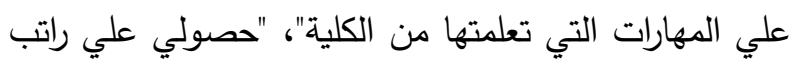
جيد من عملي"، "مجال العمل ليس له علاقة بالتخصص"،

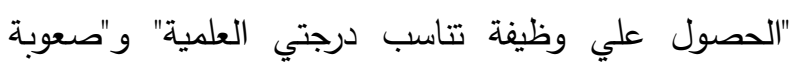

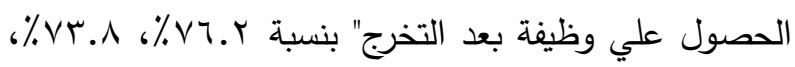
ש. علي الترتيب.

وفيما يتعلق بالتوزيع العددي والنسبي لدرجة الرضا

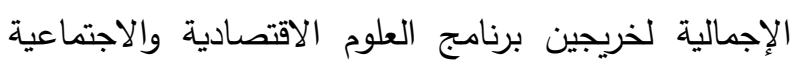

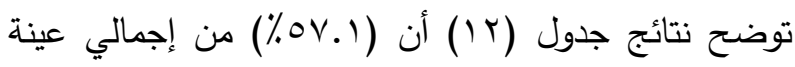

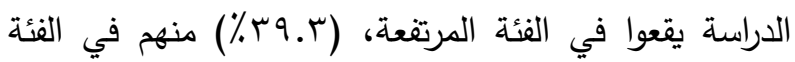

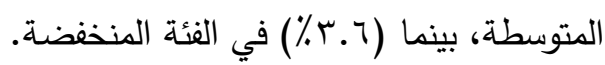

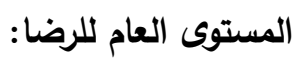

تم حساب المستوى العام للرضا من خلال إيجاد المتوسط

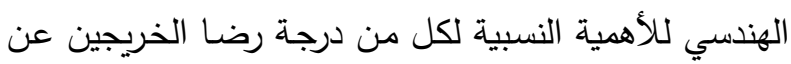

جدول r ا ـ التوزيع العددي والنسبي لدرجة الرضا الإجمالية لخريجين برنامج العلوم الاقتصادية والاجتماعية

\begin{tabular}{|c|c|c|c|c|c|c|c|}
\hline \multicolumn{2}{|c|}{ 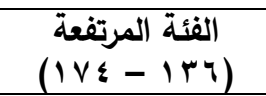 } & \multicolumn{2}{|c|}{ 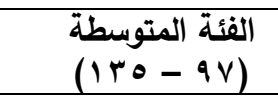 } & \multicolumn{2}{|c|}{ الفئة المنخفضة - } & \multicolumn{2}{|c|}{ المدى النظري } \\
\hline$\%$ & عدد & $\%$ & عدد & $\%$ & عدد & الحد الأعلى & الحد الأدنى \\
\hline ov. 1 & Tr & rq.r & rr & $r .7$ & r & $I V \varepsilon$ & 01 \\
\hline
\end{tabular}

المصدر : جمعت وحسبت من عينة الدراسة الميدانية.

جدول با 1. المتوسط المرجح والنسبة التقديرية لتقييم البرنامج من خلال ما قدمته الكلية للخريجين

\begin{tabular}{|c|c|c|c|c|c|c|c|c|}
\hline \multirow{2}{*}{ الترتيب } & \multirow{2}{*}{ التقديرية } & \multirow{2}{*}{ المرجح } & \multirow{2}{*}{ الأوزمون } & \multicolumn{3}{|c|}{ الاستجابات (ن= ^ ه) } & \multirow[b]{2}{*}{ العبارة } & \multirow{2}{*}{ العبارة } \\
\hline & & & & ممتاز & متوسط & مقبول & & \\
\hline 0 & 1... & T.\&T & $1+4$ & T4 & 11 & 7 & الخبرات التعليمية & 1 \\
\hline$\varepsilon$ & $10 . \mathrm{V}$ & r.OV & $1 \leq \varepsilon$ & $\mu_{\Lambda}$ & ir & 7 & جودة الارشاد الاكاديمي & r \\
\hline 1 & 94.9 & r.vq & 107 & $\varepsilon \varepsilon$ & ir & & اداء أعضاء هيئة التتربس & r \\
\hline$r$ & 人т. & $r .09$ & $1 \leqslant 0$ & $\mu_{\Lambda}$ & ir & 。 & الأنثطة والحياة الطلابية & $\varepsilon$ \\
\hline r & M.. 1 & Y.T乏 & $1 \leqslant \Lambda$ & $\varepsilon$. & ir & $\varepsilon$ & جودة البرنامج & 。 \\
\hline \multicolumn{2}{|r|}{1.1} & Y.7. & VYq & 197 & 7. & r & | غنر ككل & 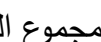 \\
\hline
\end{tabular}

المصدر : جمعت وحسبت من عينة الدراسة الميدانية. 
^. إضـافة مقرر يتتاول أثر المتغيرات العالمية والمحلية على سوق العمل والإنتاج، ومتطلباتها من الخريجين.

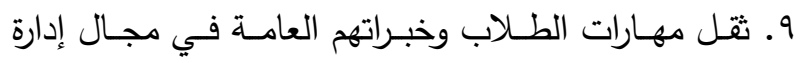
المزراع بما يزيد قدرة التنافسية في سوق العمل.

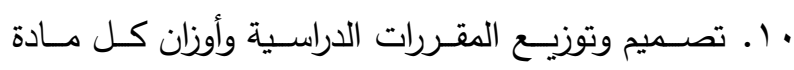
بمفاهيم جديدة تتفق مع العصر ، تقل بها مساحة الحفظ ونظ وتقتصـر على الضـروري منهـا وتتـرك المسـاحة الكافيـة

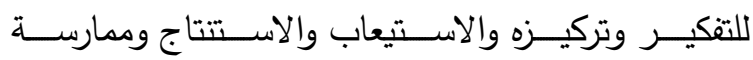

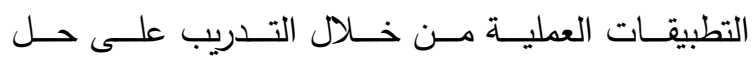
المشكلات.

ا ـ ــــميم وتوزيــع المقـررات الدراسـية وأوزان كـل مــادة بمفاهيم جديدة تتفق مع العصر ، تقل بها مساحة الحفظ وتقتصـر على الضـروري منهـا وتتـرك المســاحة الكافيـة

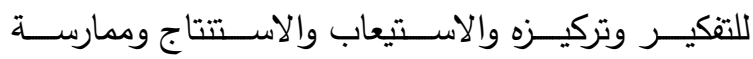

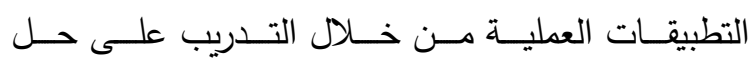
المشكلات.

\section{المراجع}

أبو زيد، عبد الباقي عبد المنعم (99V (1). تقويم مناهج شعبة المصـارف بالمدرسة الفنية المتقدمة في ضوء ضوع مطالب سوق

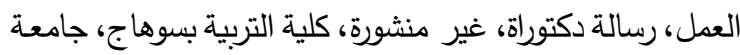

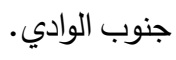

أسماء أبو بكر صديق عبدالله (9 (1) ب). درجة رضـا خرجيي كلية

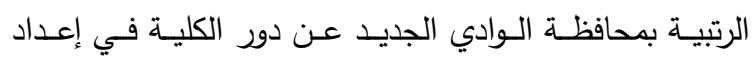

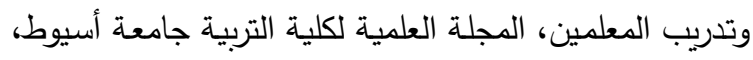

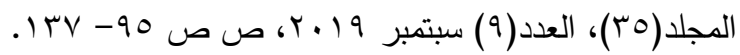

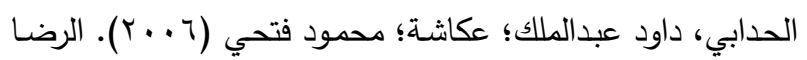

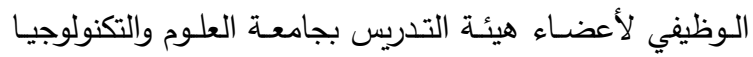
وعلاقته ببعض المتغيرات المهنية والديموجرافية، مجلة اتحاد

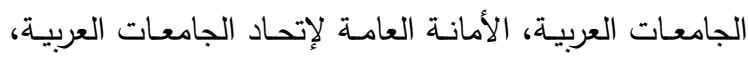

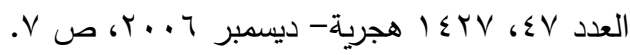

حيث جاء في الترتيب الأول "اداء أعضاء هيئة التدري" بما يمثل نحو 9.9٪\%، بينما جاء في الترتيب الثاني "جودة

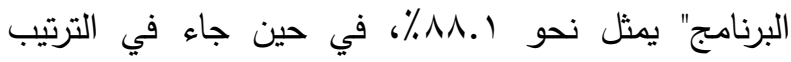
الثالث "الأنشطة والحياة الطلابية" بما يمثل س.بی^٪، في حين جاء في الترتيب الرابع "جودة الارشاد الاكاديمي" بما يمثل نحو ^o. V٪، في حين جاء في الترتيب الخامس

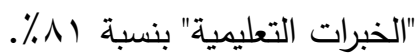

\section{التوصيات}

توصل البحث إلي عدة توصيات يمكن الاعتمـاد عليها كـإجراءات تصـحيحية للوصــول إلـي اقصسي درجـة رضــا لخريجي برنامج العلوم الاقتصادية والاجتماعية بماف يتوافق مع متطلبات سوق العمل وهي: ا ـ التوافق بين طبيعة الأعمال التي تقدمها جهات التوظيف في القطاعين العام والخاص والمهارات المتوفرة لدى الخريجين.

r ـ رفع مستوى الاتصـال بين البرنامج وبين جهات التوظيف بالفعالية المطلوبة. r. خريجي البرنامج بحاجة إلى إعادة تدريب ليتمكنوا من القيام بالأعمال المقدمة لهم. الهردي ع. النظر في المقررات الدراسية بما يتناسب مـ سوق العمل لفعل

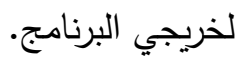
ه. إعادة النظر في البرامج التعليمية والتركيز على البرامج التطبيقية العملية وليس مجرد معلومات نظرية. 7. تتمية قدرة الطلاب على التقدم في علوم الحاسب الآلي وما يرتبط بـه من برمجيات وكذا استخدام اللغة الإنجليزيـة بشكل أفضل يتمتع به جميع الخرجين.

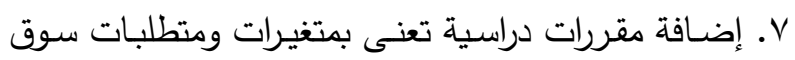

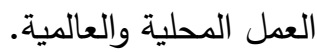




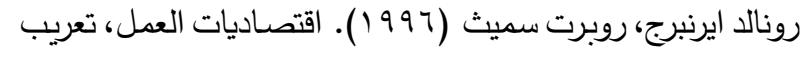

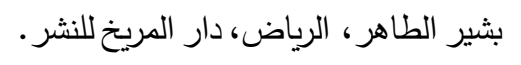

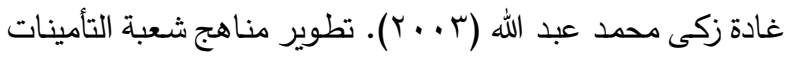

بالمدرسة الفنية المتقدمة في ضوء احتياجات سوق العمل، رسالة

$$
\text { دكتوراه، غير منشورة، كلية التربية، جامعة عين شمس. }
$$

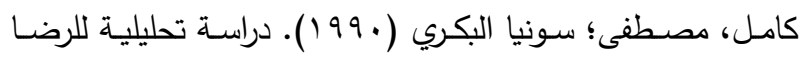

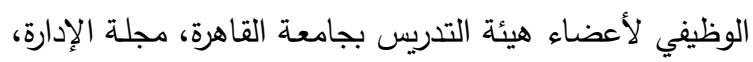

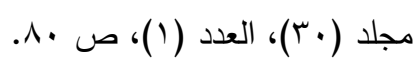

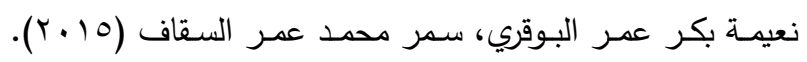

جودة الخدمة وأثرها على رضـا الطالبات في مؤسسات التعليم

العـالي دراسـة تطبيقيـة لكليـات مدينـة جدة بالمملكـة العربيـة

السعودية، المجلة العلمية لقطاع كليات التجارة، جامعة الأزهر ،

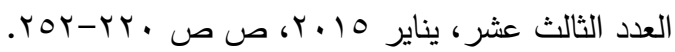

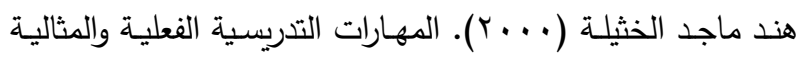

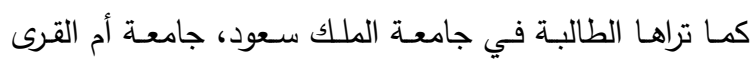

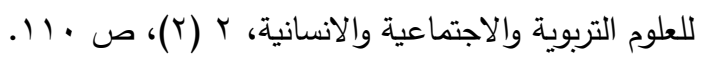

Aldosary, Adel S. (1999) "Students Academic Satisfaction: The Case of CED at KFUPM", King Abdulaziz University Journal of Engineering Sciences; Vol.11, No.1: 99- 106.

Hom, Willard C. (2003). Applying Customer satisfaction Theory to Community College planning of Counseling services", EDUCATIONAL RESOURCES INFORMATION CENTER (ERIC), $\mathrm{p} 3$.

Kuh, George D. (1999). How Are We Doing? Tracking the Quality of the Undergraduate Experience, 1960 to the Present. Review of Higher Education, p 116.

Terenzini, Patrick T. (1995). Academic and Out- of Class Influences on Students' Intellectual Orientations. Review of Higher Education, $\mathrm{p} 28$.

Ying,Y \& Chang, K: A study of suicide and socioeconomic factors, Suicide and Life-Threatening Behavior,VOL. 39 (2), PP. 214-226, 2009.
الطائي، يوسف؛ والعبادي، محمد؛ والعبادي، هاشم (1 . . †) إدارة

الجودة الثاملة في التعليم الجامعي، عمان، دار الوراق للنشر والتوزيع، الأردن.

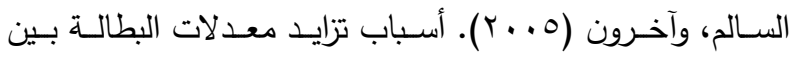

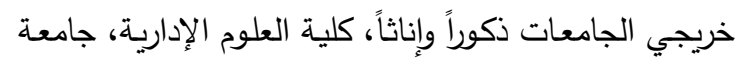
الملك سعود.

القضاة، محمد أمين؛ خلفيات، عبد الفتاح صـالح (ب ( • ץ). درجة

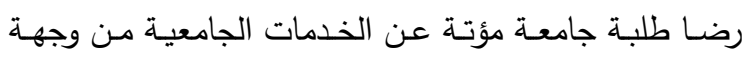

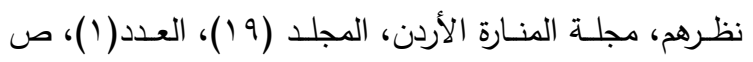

. TTY

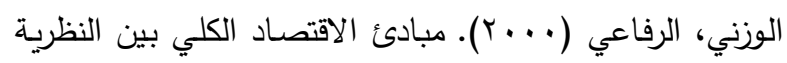
والتطبيق، دار وائل للنشر ، عمان -الأردن.

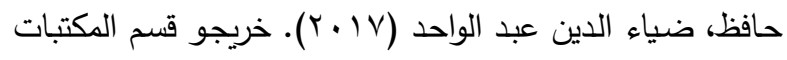
والمعلومات بجامعة عين شمس وسوق العمل دراسة تتبعية،

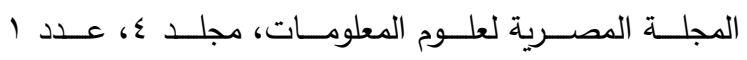

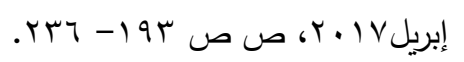

حسن، عبدالحميد سـيد؛ إبراهيم، محمد عبدالل؛ الظفري، سـيد (111) الأصول والإدارة التربوية في كلية التربية في جامعة السلطان

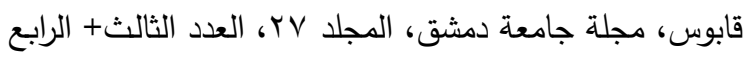

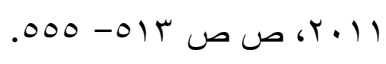

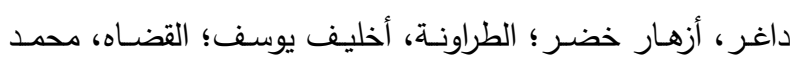

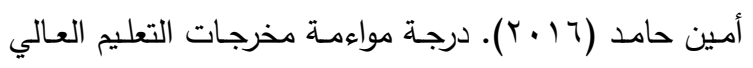

الأردني لحاجة سوق العمل، دراسـات العلوم التربويـة، المجلد

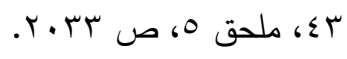


محمد عثمان عبدالفتاح، هبة نور الدين محمد: دراسة تحليلية لدرجة رضا خريجي برنامج العلوم الاقتصادية والاجتماعية...

ABSTRACT

\title{
An analytical Study of the Degree of Satisfaction of Graduates of the Economic and Social Sciences Program, Faculty of Agriculture, Ain Shams University, in Light of the Requirements of the Labor Market
}

\author{
Mohamed Osman Abdel-fatah, Heba Nour el din Mohamed
}

This research aimed to measure the degree of satisfaction of graduates of the Economic Sciences Program at the Faculty of Agriculture, Ain Shams University, evaluate the program through what the college presented from the graduate's point of view, Determine the unemployment rate for graduates of the Economic and Social Sciences Program, Faculty of Agriculture, Ain Shams University, The research was based on the descriptive approach, the social survey approach in the sample and the quantitative economic approach through selecting a sample of 56 graduates of the Economic and Social Sciences Program, representing about $33.5 \%$ of the total of 167 graduates. During the period from December 20, 2020 to January 10,2021 , by conducted an electronic questionnaire for graduates of the Economic and Social Sciences Program at the Faculty of Agriculture, Ain Shams University, on a number of groups of college graduates, and measures of central tendency were used in data processing, as it used frequency tables, estimated ratios, and weighted average, to analyze the research data.
The results showed that the unemployment rate was about $45.4 \%$ of all respondents, The results also indicated that the estimated percentage of the degree of graduate satisfaction with the courses and the extent of their relevance to the needs of the labor market are average, as the overall percentage was about $68.2 \%$, and the estimated percentage of the degree of graduate satisfaction with the performance of faculty members is strong, as the overall percentage is about $89.6 \%$, The estimated percentage of the graduates 'satisfaction with the level of service performance in the college is average, where the overall percentage is about $77.2 \%$. The estimated percentage of the degree of graduate's satisfaction with the level of knowledge, skills and training development in the program is strong, as the overall percentage is about $83.2 \%$, The estimated percentage of the degree of graduate satisfaction about The performance of the labor market is moderate, with the overall percentage reaching about $75.5 \%$, The estimated percentage of the program evaluation through what the college presented to graduates is strong, as the overall percentage was about $86.8 \%$.

Key words: Graduates Satisfaction, Labor Market, Ain Shams University, Unemployment rate. 